\title{
Property Rights and the Nature of the Firm
}

\section{Citation}

Hart, Oliver, and John Moore. 1990. Property rights and the nature of the firm. Journal of Political Economy 98(6): 1119-1158.

\section{Published Version}

doi:10.1086/261729

\section{Permanent link}

http://nrs.harvard.edu/urn-3:HUL.InstRepos:3448675

\section{Terms of Use}

This article was downloaded from Harvard University's DASH repository, and is made available under the terms and conditions applicable to Other Posted Material, as set forth at http:// nrs.harvard.edu/urn-3:HUL.InstRepos:dash.current.terms-of-use\#LAA

\section{Share Your Story}

The Harvard community has made this article openly available.

Please share how this access benefits you. Submit a story.

\section{Accessibility}




\section{CHICAgO JOURNALS}

Property Rights and the Nature of the Firm

Author(s): Oliver Hart and John Moore

Source: The Journal of Political Economy, Vol. 98, No. 6 (Dec., 1990), pp. 1119-1158

Published by: The University of Chicago Press

Stable URL: http://www.jstor.org/stable/2937753

Accessed: 24/12/2009 13:21

Your use of the JSTOR archive indicates your acceptance of JSTOR's Terms and Conditions of Use, available at http://www.jstor.org/page/info/about/policies/terms.jsp. JSTOR's Terms and Conditions of Use provides, in part, that unless you have obtained prior permission, you may not download an entire issue of a journal or multiple copies of articles, and you may use content in the JSTOR archive only for your personal, non-commercial use.

Please contact the publisher regarding any further use of this work. Publisher contact information may be obtained at http://www.jstor.org/action/showPublisher?publisherCode=ucpress.

Each copy of any part of a JSTOR transmission must contain the same copyright notice that appears on the screen or printed page of such transmission.

JSTOR is a not-for-profit service that helps scholars, researchers, and students discover, use, and build upon a wide range of content in a trusted digital archive. We use information technology and tools to increase productivity and facilitate new forms of scholarship. For more information about JSTOR, please contact support@jstor.org.

The University of Chicago Press is collaborating with JSTOR to digitize, preserve and extend access to The Journal of Political Economy. 


\section{Property Rights and the Nature of the Firm}

\section{Oliver Hart}

Massachusetts Institute of Technology

\section{John Moore}

London School of Economics

This paper provides a framework for addressing the question of when transactions should be carried out within a firm and when through the market. Following Grossman and Hart, we identify a firm with the assets that its owners control. We argue that the crucial difference for party 1 between owning a firm (integration) and contracting for a service from another party 2 who owns this firm (nonintegration) is that, under integration, party 1 can selectively fire the workers of the firm (including party 2), whereas under nonintegration he can "fire" (i.e., stop dealing with) only the entire firm: the combination of party 2 , the workers, and the firm's assets. We use this idea to study how changes in ownership affect the incentives of employees as well as those of owner-managers. Our framework is broad enough to encompass more general control structures than simple ownership: for example, partnerships and worker and consumer cooperatives all emerge as special cases.

We both would like to thank the National Science Foundation and the LSE SuntoryToyota International Centre for Economics and Related Disciplines for financial assistance. Hart is also very grateful for financial support from the Guggenheim Foundation, the Olin Foundation, Harvard Law School, and the Center for Energy Policy Research at MIT. Part of this paper was written while Hart was visiting Harvard Law School, and he would like to acknowledge their hospitality. We would also like to thank Erik Brynjolfsson, Drew Fudenberg, Bengt Holmstrom, Andreu Mas-Colell, Andrei Shleifer, Birger Wernerfelt, Jeff Zwiebel, and two anonymous referees for helpful comments. 


\section{Introduction}

What is a firm? How do transactions within a firm differ from those between firms? These questions, first raised by Coase (1937) over 50 years ago, have been the subject of much discussion by economists, but general answers at the level of formal modeling still have to be provided. The purpose of this paper is to provide a framework for addressing such questions. Following Grossman and Hart (1986), we identify a firm with the assets it possesses and take the position that ownership confers residual rights of control over the firm's assets: the right to decide how these assets are to be used except to the extent that particular usages have been specified in an initial contract. We argue that the crucial difference for party 1 between owning a firm (integration) and contracting for a service from another party 2 who owns this firm (nonintegration) is that, under integration, party 1 can selectively fire the workers of the firm (including party 2 ) if he dislikes their performance, whereas under nonintegration he can "fire" (i.e., stop dealing with) only the entire firm: the combination of party 2 , the workers, and the firm's assets. We use this idea in a multiasset, multiindividual economy to study how changes in ownership affect the incentives of nonowners of assets (employees) as well as the incentives of owner-managers.

Our analysis is consistent with and builds on the ideas developed by Williamson $(1975,1985)$ and Klein, Crawford, and Alchian (1978), as well as Grossman and Hart (1986). ${ }^{1}$ Williamson and Klein et al. made the important observation that firms matter when parties must make specific investments and, because of the impossibility of writing detailed long-term contracts, the quasi rents from these investments cannot be divided up appropriately in advance. Integration is seen as a way of reducing the opportunistic behavior and holdup problems that can arise in such circumstances. Grossman and Hart argued that a change in ownership brings costs as well as benefits. Transferring ownership of an asset from party 2 to party 1 increases 1's freedom of action to use the asset as he or she sees fit and therefore increases 1's share of ex post surplus and ex ante incentive to invest in the relationship; but 2's share of ex post surplus and incentive to invest falls. Hence concentrating ownership in l's hands will be good to the extent that l's investment decision is important relative to 2's, but will be bad if the opposite is the case. In this way, the costs and benefits of integration can be understood as two sides of the same coin.

The Grossman-Hart analysis is restrictive in that it views the costs and benefits of integration solely in terms of the incentive effects on

\footnotetext{
${ }^{1}$ For recent reviews of this literature, see O. Hart (1989) and Holmstrom and Tirole (1989).
} 
top management. In this paper, we allow for the possibility that an asset is worked on by several people, some of whom (employers) have ownership rights and others of whom (employees) do not. A major part of our analysis will be concerned with how employees' incentives change as integration occurs, that is, as asset ownership becomes more or less concentrated.

In addition, we specialize the meaning of residual control rights relative to Grossman and Hart. We suppose that the sole right possessed by the owner of an asset is his ability to exclude others from the use of that asset. That is, the owner of a machine can decide who can and who cannot work on that machine, the owner of a building can decide who can and who cannot enter the building, the owner of an insurance company's client list can decide who has and who does not have access to the list, and so forth. ${ }^{2}$ We shall see that control over a physical asset in this sense can lead indirectly to control over human assets. For example, if a group of workers requires the use of an asset to be productive, then the fact that the owner, party 1 say, has the power to exclude some or all of these workers from the asset later on (i.e., he can fire them selectively) will cause the workers to act partially in party l's interest. The reason is that by doing so workers put themselves in a stronger bargaining position later on with the person who determines whether they have access to the asset: party 1 . This should be contrasted with a situation in which party 1 contracts for a service from someone else who owns the asset; under these conditions, the asset's workers will tend to act in the other person's interest since it is that person who is the boss they bargain with in the future. Hence, this view of the firm as a collection of physical assets leads to the intuitive conclusion that a person will have more "control" over an asset's workers if he employs them (i.e., owns the asset they work with) than if he has an arm's-length contract with another employer of the workers. $^{3}$

We shall use the following model to formalize these ideas. We consider a situation in which agents take actions today that affect their (actual or perceived) productivity or value tomorrow. These actions might represent an investment in human capital, participation in on-

\footnotetext{
${ }^{2}$ The notion that the boss of a firm can exclude employees from access to the firm's assets may be found in Alchian and Demsetz (1972).

${ }^{3}$ It should be emphasized that the approach taken in this paper (and in Grossman and Hart [1986]) distinguishes between ownership in the sense of possession of residual control rights over assets and ownership in the sense of entitlement to an asset's (verifiable) profit stream. In practice, these rights will often go together, but they do not have to. The property rights approach takes the point of view that the possession of control rights is crucial for the integration decision. That is, if firm 1 wants to acquire part of firm 2's (verifiable) profit stream, it can always do this by contract. Firm 1 needs to integrate only if it wants to acquire control over firm 2's assets.
} 
the-job training, or an activity that provides information about the agent's characteristics. For example, an agent may learn how to be a good production line worker, sales manager, or corporate lawyer tomorrow by learning certain skills today or simply by carrying out those jobs today. Or, by working hard or following instructions, an agent may signal his type, for example, that he is able, that his cost of effort is low, or that he is hardworking, trustworthy, or loyal. We also suppose that it is costly for agents to write detailed long-term contracts that precisely specify current and future actions as a function of every possible eventuality and that, as a result, the contracts written are incomplete and will be subject to renegotiation later on. Finally, we suppose that at least some of the actions taken today "pay off" in the future only if the agents have access to particular assets; that is, some skill or productivity acquisition is asset-specific (as in Becker [1964]) as well as possibly person-specific (the asset specificity may come from the fact that the assets have special characteristics or that workers have sunk costs to locate near them).

These assumptions have the following implications. First, the incompleteness of contracts means that the future return on an individual's current action will depend on his "marketability" or bargaining position tomorrow in ways that cannot be controlled via the original contract. Second, the existence of asset specificity means that an agent's marketability or bargaining position will depend on which assets he has access to and hence will be sensitive to the allocation of asset ownership. As a result, an agent's actions will depend not only on whether he owns a particular asset but, in the event that he does not own it, on who does. (In this paper, all ex ante actions by agents will involve [actual or perceived] changes in human capital. Physical assets will be supposed to be already in place; the only question is who owns them.)

This last point, plus some of the paper's other ideas, can be illustrated by an example. Suppose that two workers 1 and 2, in conjunction with some specific asset, can provide a service to consumer 3 at date 1 . To aid the exposition we shall imagine that the asset is a luxury yacht, worker 1 is a chef, worker 2 is the skipper, the service is gourmet seafare, and consumer 3 is a very important customer, for example, a tycoon who entertains frequently. For this service to be useful, the chef must, at cost 100 to himself, take an asset-specific action at date 0 , for example, acquire a skill (the skill might be preparation of a particular cuisine). Such a skill would typically be partially transferable, and the argument below generalizes to this case. However, for simplicity, we suppose that it is not transferable at all (there are no other yachts cruising nearby). Suppose also that (i) the value of the service to the tycoon is 240 and, moreover, no other consumer values 
the service at all (only the tycoon can afford to fly to these waters); and that (ii) there are many substitutes for the skipper's skills at date 1 , in the sense that the chef and tycoon can easily go to the date 1 spot market and replace the skipper if necessary. Suppose in addition that transaction costs prevent the writing of any long-term contract at date 0 and that the discount rate is zero.

We have set things up so that it is efficient for the chef to acquire the skill at date 0 (the cost of the action, 100, is less than the benefit, 240). However, if the skipper owns the yacht, the chef will not act. The reason is that, looking ahead to date 1 , the chef will recognize that in order to realize the gains from his date 0 action he needs to reach agreement with the skipper and the tycoon: the skipper because the chef needs access to the asset the skipper owns and the tycoon because without the tycoon's cooperation the service is useless. If the date 1 gains are split three ways (as a symmetric bargaining solution predicts), this means that the chef will receive a return of $1 / 3(240)$, which does not cover the initial cost of 100 .

In contrast, if the tycoon owns the yacht, the chef will act. The reason is that in this case the chef needs the cooperation only of the tycoon at date 1 to realize the gain from his investment (since the skipper can be replaced). If there is a two-way split (again as predicted by a symmetric bargaining solution), the chef's return will now be $1 / 2(240)>100$.

This example captures the idea that the chef is more likely to take an action specific to the tycoon (in the sense that the tycoon is the direct beneficiary of this action) - or, to put it another way, act in the tycoon's interest-if the tycoon is his boss than if the skipper is. (The tycoon is his boss in the sense that the tycoon owns the asset the chef works with.)

Notice that the chef would also be motivated to act if he owned the asset, since this again allows him to cut the skipper out of the bargaining and receive $1 / 2(240)$. In other words, ownership by either the chef or the tycoon leads to an efficient outcome. Suppose, however, that we modify the example so that the skipper also has a date 0 action to take; for example, at cost 100 the skipper can increase the value to the tycoon of the service by another 240 (so that the total value rises to 480; maybe he learns the history of the local islands to plan a better itinerary). Then an analogous argument to the one given above shows that the skipper will be induced to take this action if either he or the tycoon owns the asset, but not if the chef does. We are thus led to the conclusion that, when both the chef and the skipper take actions specific to the tycoon, it is strictly better that the tycoon owns the yacht than that either the chef or the skipper does. We see then that it may be efficient to give ownership of assets to agents who are indispens- 
able even though they may not make important investment or effort decisions.

We can further modify this example to illustrate another conclusion of the analysis: assets that are highly complementary should be owned together. Suppose that the chef and skipper's actions are no longer specific to the tycoon (i.e., other customers can use the yacht as well), but now allow the tycoon also to take an action (the action might be to decide how much entertaining to arrange during the coming year). Continue to assume that the benefit of each agent's action is 240 , and denote agent $i$ 's costs by $c_{i}$ (so if all three agents act, the benefit of the service to the tycoon is 720). Suppose that the yacht consists of two pieces, the galley and the hull, say. Neither piece is of any use without the other. Would it ever be optimal for the chef to own the galley and the skipper to own the hull?

The answer is no. Under separate ownership, the conditions for the chef, skipper, and tycoon to act are $1 / 2(240)>c_{1}, 1 / 2(240)>c_{2}$, and $1 / 3(240)>c_{3}$, respectively, since the chef and skipper know that each must reach agreement with the other one in order to gain access to the entire yacht and get the 240 return on their individual actions, and the tycoon knows that he must reach agreement with both the chef and the skipper to get the 240 return on his action. It would be better to give the entire yacht to either the chef or the skipper. Consider giving the chef the hull as well as the galley. Then the chef's incentive to act rises: he now acts as long as $240>c_{1}$ (he can realize the 240 without bargaining with either the skipper or the tycoon; recall that the chef's action is no longer specific to the tycoon). The skipper's incentive is unaffected since, when the skipper owned the hull, he had to reach agreement with the chef (who owned the galley) anyway: the skipper acts as long as $1 / 2(240)>c_{2}$. The interesting effect is on the tycoon. Now he will have to reach agreement only with the chef, as opposed to the chef and the skipper, and so will act as long as $1 / 2(240)>c_{3}$. Clearly giving both pieces of the asset to one agent (the chef in this case) leads to fewer holdups and greater efficiency.

This example-even though it is very stylized-contains a number of the main ingredients of the model presented in the paper. We believe that it throws light on why it sometimes pays a firm (represented by the tycoon) to produce services in-house, and other times to contract outside through the market.

In the example above, the bargaining problem at date 1 is relatively simple: there are only three agents, and a coalition can obtain either all the surplus from some agent's action or none. In general, more complicated situations will arise in which partial returns can be realized by subcoalitions of the grand coalition. In the model presented below, we take a cooperative rather than a noncooperative approach 
to this bargaining problem, adopting the Shapley value as our solution concept. The main ideas of the paper hold true under a number of other divisions of the surplus, however; we discuss the robustness of our results in note 23 and in the Conclusion (Sec. V).

The paper is organized as follows. The formal model and our general results are laid out in Sections II and III. In Section IV, we apply and develop these results in some special cases. Section $V$ contains concluding remarks. Appendix A includes a number of the proofs of the propositions, while Appendix B briefly describes an extension of the basic model of human capital investment to learning by doing and signaling activities.

\section{The Model}

We shall consider a part of the economy comprising a set $\underline{S}$ of $I$ riskneutral individuals or agents $i=1, \ldots, I$ and a set $\underline{A}$ of $N$ assets $\left(a_{1}, \ldots\right.$, $\left.a_{n}, \ldots, a_{N}\right)$. There are two periods, dates 0 and 1 . All costs and benefits are measured in date 1 dollars.

At date 0 , each agent $i$ takes an action $x_{i}$. At date 1 , production and trade occur. The action $x_{\imath}$ affects the agent's productivity or value at date 1. As explained in the Introduction, this action might represent an investment in human capital, on-the-job training, or participation in an activity that increases perceived rather than actual productivity in the future.

For ease of exposition we shall adopt the first interpretation: we take $x_{\imath}$ to be a pure investment in human capital. In Appendix B, however, we discuss how the analysis can be extended to include some of the other interpretations. As a further simplification, we confine attention to the case in which an agent chooses only how much to invest (or under the other interpretations what level of service to provide). That is, we suppose that $x_{i}$ is a scalar lying in $\left[0, \bar{x}_{2}\right]$, where $\bar{x}_{i}$ $\geq 0$. Additional issues arise if an agent can also choose what type of investment to make (or type of service to provide); we discuss these briefly in the Conclusion.

Denote the cost to agent $i$ of action $x_{i}$ by $C_{\imath}\left(x_{i}\right)$. We make the following assumption.

Assumption 1. $C_{i}\left(x_{i}\right) \geq 0$ and $C_{\imath}(0)=0 . C_{i}$ is twice differentiable. If $\bar{x}_{i}>0$, then $C_{i}^{\prime}\left(x_{i}\right)>0$ and $C_{i}^{\prime \prime}\left(x_{i}\right)>0$ for $x_{\imath} \in\left(0, \bar{x}_{\imath}\right)$, with $\lim _{x_{i} \rightarrow 0} C_{\imath}^{\prime}\left(x_{\imath}\right)$ $=0$ and $\lim _{x_{i} \rightarrow \bar{x}_{i}} C_{i}^{\prime}\left(x_{i}\right)=\infty$.

As discussed in the Introduction, we adopt the incomplete contracting perspective of Grossman and Hart (1986). First, we suppose that the investment decisions $x_{i}$ are too complicated to be specified in a date 0 contract. Hence these variables are chosen noncooperatively by the agents at date 0 . Second, the future is sufficiently uncertain and 
transaction costs sufficiently great that plans about date 1 production and trade also cannot be included in a date 0 contract. ${ }^{4}$ Hence a new contract must be written to consummate the gains from trade at date 1. Such a contract is supposed to be feasible since once the uncertainty is resolved at date 1 , contingent statements are no longer required. ${ }^{5}$ Third, although an agent $i$ 's investment $x_{i}$ is complex, we assume that by date 1 it is observable to the other agents with whom he deals, and hence the date 1 contract is negotiated under symmetric information. ${ }^{6}$ Finally, we rule out profit-sharing agreements at date 0 : agreements that share date 0 investment costs or date 1 revenues. ${ }^{7}$

The implication of these various assumptions is that the gains from trade at date 1 will be determined according to a multiperson bargaining process conducted under symmetric information. We take a cooperative approach to this bargaining problem, adopting the Shapley value as our solution concept. In order to apply this, we first need to specify the gains from trade that various coalitions $S$ of agents can achieve by themselves.

Let $x=\left(x_{1}, \ldots, x_{I}\right)$. Consider a coalition $S$ of agents who control a subset $A$ of the assets at date 1 . We shall suppose that the absence of a date 0 contract means that this coalition can use the assets in $A$ as it likes; in particular, it can exclude all agents outside $S$ from access to them. We also suppose that if the coalition $S$ forms at date 1 , it chooses an efficient ex post allocation (as noted, a contract to this effect is feasible at date 1). Such an allocation may be complex; for example, agents $i$ and $j$ may have to work with asset $a_{n}$ and sell the item they produce to agent $k$, who works on it some more and sells it to agent $l$. We do not need to specify the details of this allocation. It

${ }^{4}$ To do this would require numerous contingent statements of the following form: Agent 1 must provide agent 2 with service $s$ (described in detail) in state of the world $t$ (described in detail); this would be prohibitively expensive. Note that there is no inconsistency in assuming, on the one hand, that date 0 contingent statements are infeasible and, on the other hand, that agents have perfect foresight about the consequences of this lack of feasibility (see Grossman and Hart 1986); we shall be making the latter assumption in what follows.

${ }^{5}$ For notational simplicity, we choose not to model the ex ante uncertainty explicitly; it will be clear that none of our analysis would be affected were we to replace objective functions by their expectations.

${ }^{6}$ That is, the $x_{i}$ are observable even though they are not verifiable.

${ }^{7}$ Such agreements will be useless if (i) date 0 investment costs are in the form of effort and training costs that are unverifiable and (ii) date 1 revenues are also unverifiable; e.g., they represents "perks" or can be diverted so that they do not show up in the accounts. In fact, even if date 1 revenues are verifiable, profit-sharing agreements are likely to be of limited value if agents can threaten not to trade (or to trade an unsuitable service) at date 1 . (Recall that the date 0 agreement cannot specify the precise nature of date 1 trade.) In this case the date 1 gains from trade are likely to be determined by ex post bargaining, regardless of any date 0 agreement. A similar line of argument suggests a limited role for revelation mechanisms, also ruled out in this paper. 
will be enough to keep track of the maximum (dollar) value that the coalition can generate in this way: we represent it by $v(S, A \mid x)$, where we suppose that each agent's costs and benefits are measured in money terms. ${ }^{8}$

In coalition $S$, agent $i$ 's marginal return on investment is given by

$$
\frac{\partial}{\partial x_{1}} v(S, A \mid x) \equiv v^{\prime}(S, A \mid x),
$$

say. For each $i, S, A$, and $x$ we make the following assumptions.

Assumption 2. $v(S, A \mid x) \geq 0$ and $v(\varnothing, A \mid x)=0$, where $\varnothing$ is the empty set. $v(S, A \mid x)$ is twice differentiable in $x$. If $\bar{x}_{2}>0$, then $v^{i}(S$, $A \mid x) \geq 0$ for $x_{\imath} \in\left(0, \bar{x}_{\imath}\right) . v(S, A \mid x)$ is concave in $x$.

Assumption 3. $v^{2}(S, A \mid x)=0$ if $i \notin S$.

Assumption 4. $\left(\partial / \partial x_{j}\right) v^{i}(S, A \mid x) \geq 0$ for all $j \neq i$.

Assumption 5. For all subsets $S^{\prime} \subseteq S, A^{\prime} \subseteq A, v(S, A \mid x) \geq v\left(S^{\prime}\right.$, $\left.A^{\prime} \mid x\right)+v\left(S \backslash S^{\prime}, A \backslash A^{\prime} \mid x\right)$.

Assumption 6. For all subsets $S^{\prime} \subseteq S, A^{\prime} \subseteq A, v^{\imath}(S, A \mid x) \geq v^{2}\left(S^{\prime}\right.$, $\left.A^{\prime} \mid x\right)$.

Assumption 3 says that an agent's marginal investment affects only the value of coalitions of which he is a member. It captures the idea that an agent's investment enhances his own productivity rather than that of any asset he works with (it is a human capital, rather than a physical capital, investment). Assumption 4 says that investments are complementary at the margin. Assumption 5 is a natural superadditivity assumption: a coalition could always divide if the values of the partition added up to more than the value of the whole. Assumption 6 is stronger than the others: it says that the marginal return on investment increases with the number of other agents and assets in the coalition; in conjunction with assumption 5, this means that marginal and total values are positively correlated. We discuss assumption 6 further in the Conclusion.

Note that in writing the value of the coalition $S$ as $v(S, A \mid x)$, we are allowing for the possibility that $S$ recruits additional members for the coalition from outside the agents $\underline{S} \backslash S$; for example, $S$ could hire from the date 1 spot labor market. Such new members will typically be less productive than the agents $\underline{S} \backslash S$ whom they are replacing-they will not have acquired the relevant asset-specific or person-specific skills, or come with the appropriate assets-and it is for this reason that we expect strict superadditivity to hold: $v(\underline{S}, \underline{A} \mid x)>v(S, A \mid x)+v(\underline{S} \backslash S$, $\underline{A} \backslash A \mid x)$.

Superadditivity implies that the maximum total value at date 1 is

${ }^{8}$ Note that there is no contradiction in assuming that costs and benefits are nonverifiable and yet can be measured in money terms. 
given by $v(\underline{S}, \underline{A} \mid x) \equiv V(x)$, say. The first-best overall social surplus is then

$$
\underset{x}{\operatorname{maximum}} W(x) \equiv V(x)-\sum_{\imath=1}^{I} C_{\imath}\left(x_{i}\right) .
$$

Let the maximum be attained at $x=x^{*}$. By assumptions 1 and $2, x^{*}$ is unique and is characterized by the first-order conditions

$$
\left.\frac{\partial}{\partial x_{\imath}} V(x)\right|_{x=x^{*}}=v^{\imath}\left(\underline{S}, \underline{A} \mid x^{*}\right)=C_{\imath}^{\prime}\left(x_{\imath}^{*}\right) \text { for all } i .
$$

We shall be interested in a noncooperative situation in which agent $i$ chooses $x_{i}$ at date 0 , anticipating that at date 1 the value $V(x)$ will be divided among the $I$ agents according to their Shapley values. ${ }^{9}$ In order to compute each agent's payoff, we first need to know who controls which assets.

\section{A. The Control Structure}

We represent the ownership and control structure by a mapping $\alpha$ from the set of subsets of $\underline{S}$ to the set of subsets of $\underline{A}$, where $\alpha(S)$ is the subset of the assets $\left\{a_{1}, \ldots, a_{N}\right\}$ that the coalition $S$ controls at date 1 . For any partition $S \cup(\underline{S} \backslash S)$ of the agents $\underline{S}$, each of the assets is controlled by at most one of the subsets $S,(\underline{S} \backslash S)$. Hence,

$$
\alpha(S) \cap \alpha(\underline{S} \backslash S)=\varnothing .
$$

Also, the assets controlled by any subset $S^{\prime}$ of a coalition $S$ must also be controlled by the whole coalition:

$$
\alpha\left(S^{\prime}\right) \subseteq \alpha(S)
$$

Note that it follows trivially from (2) and (3) that $\alpha(\varnothing)=\varnothing$.

Definition. A (deterministic) control structure is a mapping $\alpha$ from the set of subsets of $\underline{S}$ to the set of subsets of $\underline{A}$ satisfying (2) and (3).

Examples of control structures include the case in which one person $i$ owns some asset $a_{n}$ (i.e., $a_{n} \in \alpha(S) \Leftrightarrow i \in S$ ) or person $i$ has a share (or vote) $\sigma_{n}(i)$ in asset $a_{n}$ and majority rule applies (i.e., $a_{n} \in \alpha(S) \Leftrightarrow$ $\left.\Sigma_{\imath \in S} \sigma_{n}(i)>.5\right)$. Other arrangements are possible, however. In the next section, we shall want to consider stochastic control structures. A stochastic control structure is simply a random mapping $\tilde{\alpha}$, whose

${ }^{9}$ See Shapley (1953). For a recent summary of the Shapley value literature and further references, see S. Hart (1987). See also the volume edited by Roth (1988). For examples of applications of the Shapley value, see Aumann and Kurz (1977) and Rydquist (1987). 
realization $\alpha$ is a deterministic control structure (e.g., each individual could be the sole owner of asset $a_{n}$ with probability $\left.1 / I\right){ }^{10}$

Given a (deterministic) control structure $\alpha$, the date 1 value of a coalition $S$ is $v(S, \alpha(S) \mid x)$. As noted above, we suppose that agent $i$ 's share of $V(x)$ is given by his Shapley value

$$
B_{i}(\alpha \mid x) \equiv \sum_{S \mid \imath \in S} p(S)[v(S, \alpha(S) \mid x)-v(S \backslash\{i\}, \alpha(S \backslash\{i\}) \mid x)],
$$

where

$$
p(S)=\frac{(s-1) !(I-s) !}{I !}
$$

and $s=|S|$, the number of agents in $S$. In words, the Shapley value gives agent $i$ his expected contribution to a coalition, where the expectation is taken over all coalitions to which $i$ might belong. In particular, we can imagine that the agents $\underline{S}$ are ordered randomly, with each ordering being equally likely. If agent $i$ is placed $s$ th from the end, followed by the other members of coalition $S$, we say that $i$ belongs to coalition $S$ (this happens with probability $p(S)$ ); agent $i$ 's contribution to the coalition is then given by the difference $[v(S, \alpha(S) \mid x)-v(S \backslash\{i\}$, $\alpha(S \backslash\{i\}) \mid x)]$, and the Shapley value is simply the expectation of this over all random orderings. Note that saying that $i$ belongs to a particular coalition is a manner of speaking; the statement should not be taken literally since the Shapley value is predicated on the idea that the grand coalition $\underline{S}$ forms and distributes surplus efficiently. ${ }^{11}$

\footnotetext{
${ }^{10}$ In principle, the date 0 contract could make the control structure a function of prearranged date 1 payments. An example of such a control structure is a secured debt contract, in which a debtor can "buy" control of an asset (the collateral) from a creditor at a prearranged price (the debt level); see Hart and Moore (1989). Such option-to-own contracts are important when parties are wealth-constrained, and these contracts might also play a role in the present model (in which wealth constraints have been assumed away). However, since we believe that our results would in essence be unchanged by the presence of option-to-own contracts, for simplicity we rule them out.

${ }^{11}$ We should mention that our results generalize to divisions of surplus other than the Shapley value (see n. 23). Note that the assumption that there is costless bargaining at date 1 leading to an ex post efficient allocation is itself very strong. We discuss this assumption further in Sec. V.

In app. A of Hart and Moore (1988), we give a brief noncooperative justification for the use of the Shapley value. The multistage game we construct involves a sequence of take-it-or-leave-it contracts. First (at stage 0 of the game), the $I$ agents are lined up in a random order: $j_{1} j_{2} \ldots j_{l}$, say. Then at stage 1 agent $j_{1}$ makes an offer to agent $j_{2}$. The offer is in the form of a contract for $j_{2}$ to sign. No restrictions are placed on the type of contract that can be offered: among other things, the contract may specify what offer agent $j_{2}$ has to make to agent $j_{3}$ at stage 2 . Once the offer has been made, it is either accepted (signed) by agent $j_{2}$ or rejected. In either event the game then moves on to stage 2, at which point agent $j_{2}$ makes an offer (a contract) to agent $j_{3}$. This process continues until the $(I-1)$ th stage, when agent $j_{I-1}$ makes an offer to agent $j_{I}$. Finally, at stage $I$ of the game, production and trade are carried out according to the agreed
} 
At date 0 , agent $i$ chooses $x_{i}$ to maximize $B_{i}(\alpha \mid x)-C_{i}\left(x_{i}\right)$. From assumptions 1-3, the Nash equilibrium $x=x^{e}(\alpha)$, say, is characterized by the first-order conditions

$$
\begin{aligned}
\left.\frac{\partial}{\partial x_{i}} B_{i}(\alpha \mid x)\right|_{x=x^{e}(\alpha)} & =\sum_{S \mid i \in S} p(S) v^{i}\left[S, \alpha(S) \mid x^{e}(\alpha)\right] \\
& =C_{i}^{\prime}\left(x_{i}^{e}(\alpha)\right) \quad \text { for all } i .
\end{aligned}
$$

From assumption 6 and condition (3), we know that the left-hand side of (5) is less than or equal to

$$
\sum_{S \mid i \in S} p(S) v^{i}\left(\underline{S}, \underline{A} \mid x^{e}(\alpha)\right)=v^{i}\left(\underline{S}, \underline{A} \mid x^{e}(\boldsymbol{\alpha})\right)=\left.\frac{\partial}{\partial x_{i}} V(x)\right|_{x=x^{e}(\alpha)} .
$$

Comparing (1) and (5), then, for a given $x_{-i}=\left(x_{1}, \ldots, x_{i-1}, x_{i+1}, \ldots\right.$, $x_{I}$ ), we see that agent $i$ 's private marginal return on investment is less than the socially efficient level. In proposition 1 we show that assumptions 1-4 together imply that in fact the entire vector $x^{e}(\alpha)$ will be less than the first-best $x^{*}$. Moreover, any change in control structure $\alpha$ that increases each agent's private marginal return on investment will unambiguously improve welfare.

Proposition 1. For any control structure $\alpha$, there is underinvestment: the unique Nash equilibrium $x^{e}(\alpha)$ satisfies $x_{i}^{e}(\alpha) \leq x_{i}^{*}$ for each $i$. Moreover, if the control structure $\alpha$ changes to $\hat{\alpha}$, say, so that every agent's marginal return on investment increases, that is, if for each $i$

$$
\frac{\partial}{\partial x_{i}} B_{i}(\hat{\alpha} \mid x) \geq \frac{\partial}{\partial x_{i}} B_{i}(\alpha \mid x) \text { for all } x,
$$

then equilibrium investment increases, $x^{e}(\hat{\alpha}) \geq x^{e}(\alpha)$, and welfare increases, $W\left(x^{e}(\hat{\alpha})\right) \geq W\left(x^{e}(\alpha)\right)$.

Proof. See Appendix A.

The underinvestment occurs, of course, because of an externality: when agent $i$ invests more, some of his increased productivity will be dissipated in bargaining at date 1. In fact, it can be seen from (5) that he will receive the full marginal return from his investment only if he is first in the random ordering of the agents $\underline{S}$ at date $1 ;^{12}$ in all other cases, some of the benefits will flow to other agents. ${ }^{13}$

contracts. We show that in any (subgame perfect) equilibrium of this game, agent $j$ receives his Shapley value. For an alternative noncooperative justification for the use of the Shapley value, see Gul (1989).

${ }^{12}$ The reason is that from assumption 6 and condition (3), we know that $v^{i}(S$, $\left.\alpha(S) \mid x^{e}(\alpha)\right)$ is greatest when $S=\underline{S}$.

${ }^{13}$ In Grossman and Hart (1986), overinvestment, as well as underinvestment, is a possibility because assumption 6 does not hold in that paper. For more on the implications of violations in assumption 6 , see Sec. V.

Note that our proof of proposition 1 supposes that $v$ is concave (see assumption 2). 
We shall take the point of view that efficient trading at date 0 leads to a control structure $\alpha$ that maximizes $W\left(x^{e}(\alpha)\right)$. That is, if the initial $\alpha$ does not maximize $W\left(x^{e}(\alpha)\right)$, someone will propose a new $\alpha$ and a set of side payments such that everyone is better off (in this paper, the equilibrium division of surplus at date 0 will be unimportant). In the next section, we shall investigate the control structures $\alpha$ that maximize $W\left(x^{e}(\alpha)\right)$. Then in Section IV, we shall apply our general results to some special cases in order to understand better what factors determine the boundaries of a firm. ${ }^{14}$

Before we proceed, though, some simplification in notation is useful at this point. Rather than carry the last argument $x$ of the functions $B_{i}(\alpha \mid x), v(S, A \mid x)$, and $v^{i}(S, A \mid x)$ throughout the rest of the paper, we shall drop it and write simply $B_{i}(\alpha), v(S, A)$, and $v^{i}(S, A)$. Also, we define the function $B_{i}^{i}(\alpha)$ by

$$
B_{i}^{i}(\alpha) \equiv \frac{\partial}{\partial x_{i}} B_{i}(\alpha \mid x),
$$

where here and throughout the paper we use the equivalence sign (三) to denote "for all $x$."

\section{General Results}

Our aim in the following propositions is to give a partial characterization of an optimal control structure $\alpha$ : one that will provide the agents with the second-best incentives to invest at date $0 .{ }^{15}$ Of course, if there are no investments, then the control structure will be unimportant; this follows from our assumption that there is costless bargaining at date 1, leading to ex post efficiency.

Proposition 2. If only one agent $i$ has an investment, then he should own all the assets; that is, for any coalition $S, a_{n} \in \alpha(S)$ if and only if $i \in S$.

Proof. If only agent $i$ has an investment, then we want to choose a control structure $\alpha$ that maximizes his marginal return on investment:

However, it appears from Milgrom and Roberts's (in press) results on supermodular functions that this could be relaxed.

${ }^{14}$ Note that we assume that a control structure agreed on by the parties can be enforced. In particular, we rule out secret asset transfers between the agents. For example, if agents 1,2 , and 3 agree that agent 1 should own asset $a$, we do not consider the possibility that agent 2 may buy the asset secretly from agent 1 , with agent 3 finding out about this only after he makes his investment decision.

${ }^{15}$ Note that many of the propositions are stated in the form that a control structure should have a certain property. This should be understood to mean that, in general, the property will be true of at least one (but not necessarily all) of the $\alpha$ 's that maximize welfare. Typically, though, the optimal control structure will be unique, in which case our results are clear-cut. 


$$
B_{i}^{i}(\alpha)=\sum_{S \mid i \in S} p(S) v^{i}(S, \alpha(S))
$$

From assumption 6 , this will be maximized by putting $\alpha(S)=\underline{A}$ for all $S$ containing $i$. Q.E.D.

The idea is simple. The best way to induce the agent to invest is to give him use of all the assets, no matter to which coalition he may belong, for then he will have the greatest marginal incentive to invest to improve his bargaining position at date 1 . That is, by giving him control over all the assets, the classic holdup problem can be at least partially alleviated.

Proposition 3. Take any coalition of agents. Then each asset should be controlled by either the coalition or its complement.

Proof. Suppose that $a_{n} \notin \alpha(S) \cup \alpha(\underline{S} \backslash S)$ for some asset $a_{n}$ and coalition $S$. Then consider a new control structure $\hat{\alpha}$ that is the same as $\alpha$ except that $S$ and all supersets $S^{+}$of $S$ now control $a_{n}$. It is straightforward to confirm that $\hat{\alpha}$ satisfies requirements (2) and (3). (Since $\alpha$ satisfies [3], we know that $a_{n} \notin \alpha\left(\underline{S} \backslash S^{+}\right)$for all supersets $S^{+}$, and hence $\hat{\alpha}$ does not violate [2].)

The change $B_{i}^{i}(\hat{\alpha})-B_{i}^{i}(\alpha)$ in marginal return on investment for some agent $i$ in $S$ will be

$$
\sum_{S^{+} \mid S \subseteq S^{+}} p\left(S^{+}\right)\left[v^{i}\left(S^{+}, \alpha\left(S^{+}\right) \cup\left\{a_{n}\right\}\right)-v^{i}\left(S^{+}, \alpha\left(S^{+}\right)\right)\right],
$$

which is nonnegative by assumption 6 . For no agent will the change in marginal return be negative. From proposition 1 , welfare will be higher under the new control structure $\hat{\alpha}$ than under $\alpha$. Q.E.D.

Again, the idea is simple. At the margin, an agent needs to be in a strong bargaining position at date 1 if he is to be induced to invest at date 0 . This means giving control of as many assets as possible to the coalitions to which he might belong. It is therefore wasteful not to give control of an asset $a_{n}$ to either $S$ or $\underline{S} \backslash S$.

Proposition 3 is a useful simplifying result. In particular, we can rule out control structures in which more than one agent has veto power over an asset, that is, in which no coalition can control the asset unless all those agents with veto power belong to the coalition. In other words, we can rule out certain types of joint ownership.

Proposition 4. Not more than one agent should have veto power over an asset.

Proof. Suppose that agents $i$ and $j$ both have veto power over an asset $a_{n}$. Then take any coalition $S$ that has agent $i$ as a member, but not agent $j$. Since $i$ and $j$ both have veto power, $a_{n}$ is not contained in $\alpha(S)$ or in $\alpha(\underline{S} \backslash S)$. But this contradicts proposition 3. Q.E.D.

Proposition 4 reflects the fact that in our model, investment is made in human rather than physical capital (see assumption 3). The model 
can be generalized to include this latter possibility but then, among other things, proposition 4 may no longer hold. ${ }^{16}$ For simplicity, in this paper we have chosen not to pursue the possibility of relaxing assumption 3 .

There are two further cases (in addition to proposition 2) in which we can be sure that an agent should own a particular asset: namely, in which the asset is idiosyncratic to him and in which he is indispensable to the asset.

Definition. An asset $a_{n}$ is idiosyncratic to an agent $i$ if for all other agents the asset is irrelevant to their marginal benefit. That is, for all agents $j$ in any coalition $S$ and for all sets $A$ of assets containing $a_{n}$,

$$
v^{j}(S, A) \equiv v^{j}\left(S, A \backslash\left\{a_{n}\right\}\right) \text { for all } j \neq i .
$$

Proposition 5. If an asset is idiosyncratic to an agent, then he should own it.

Definition. An agent $i$ is indispensable to an asset $a_{n}$ if, without agent $i$ in a coalition, asset $a_{n}$ has no effect on the marginal product of investment for the members of that coalition. That is, for all agents $j$ in any coalition $S$ and for all sets $A$ of assets containing $a_{n}$,

$$
v^{j}(S, A) \equiv v^{j}\left(S, A \backslash\left\{a_{n}\right\}\right) \quad \text { if } i \notin S .
$$

Proposition 6. If an agent is indispensable to an asset, then he should own it.

If an asset is idiosyncratic to an agent, then, a fortiori, he is indispensable to that asset. So it is enough to prove proposition 6 .

Proof of proposition 6 . Suppose that agent $i$ is indispensable to an asset $a_{n}$, but under control structure $\alpha$ he does not own it. Then consider a new control structure $\hat{\alpha}$, which is the same as $\alpha$, except that $a_{n}$ is now owned by $i$. It is straightforward to confirm that $\hat{\alpha}$ satisfies requirements (2) and (3).

The change $B_{j}^{j}(\hat{\alpha})-B_{j}^{j}(\alpha)$ in marginal return on investment for some agent $j \neq i$ will be

$$
\begin{aligned}
& \sum_{\left.S\right|_{a_{n} \notin \alpha(S)} ^{i, j \in S}} p(S)\left[v^{\jmath}\left(S, \alpha(S) \cup\left\{a_{n}\right\}\right)-v^{\jmath}(S, \alpha(S))\right] \\
& -\sum_{\left.S\right|_{a_{n} \in \alpha(S)} ^{i \notin S ; j \in S}} p(S)\left[v^{j}(S, \alpha(S))-v^{j}\left(S, \alpha(S) \backslash\left\{a_{n}\right\}\right)\right] .
\end{aligned}
$$

\footnotetext{
${ }^{16}$ For example, suppose that there are just two agents, and at date 0 they together "invest" in building a physical asset ready for sale at date 1 . Whoever owns the asset at date 1 will get the proceeds. Here, ownership by one agent may clearly be a bad arrangement since the other agent would have no incentive to invest. It may be better to have joint ownership, so that they split the proceeds from the sale at date 1 .
} 
The second summation is zero since $i$ is indispensable to $a_{n}$. The first is nonnegative by assumption 6 . So agent $j$ 's marginal incentive will not be reduced by the change in control structure.

Agent $i$ 's own marginal incentive to invest cannot fall as a result of now owning asset $a_{n}$. Hence by proposition 1 , welfare will be higher under the new control structure $\hat{\alpha}$ than under $\alpha$. Q.E.D.

We saw this result in the first part of the example of the Introduction. There agent 3 (the tycoon) was indispensable, and it was optimal to make him the owner of the asset.

The intuition behind the result is that if agent $i$ is indispensable to an asset $a_{n}$, then in order for an agent $j$ to derive marginal benefit from this asset he has to be in a coalition that both contains $i$ and controls $a_{n}$. Not making $i$ the owner of $a_{n}$ would serve only to reduce the number of such coalitions. This would reduce $j$ 's incentive to invest because at the margin $j$ invests to improve his bargaining position at date 1 . Of course, making $i$ the owner of $a_{n}$ will enhance his own incentive to invest since then the asset would always be controlled by any coalition of which he is a member.

Proposition 6 is interesting because it tells us that the importance of an agent's action is only one force determining an agent's ownership rights. A second force is the agent's importance as a trading partner. In particular, if a subset of agents has investment decisions, one cannot conclude that ownership rights of assets should be concentrated only on this subset. In fact, if some agent outside the subset is indispensable, proposition 6 tells us that it is better to give all ownership rights to this agent. ${ }^{17}$

Proposition 6 begs the question, What happens if a whole group of agents are indispensable to an asset? In this case, one (or more) of the group should always be given control over the asset. In the extreme, when all the agents are indispensable to all the assets, the control structure is unimportant. The reason for this is that an agent's marginal product of investment will be enhanced by an asset only if he is in the grand coalition $\underline{S}$ (in any subcoalition, there will be one or more indispensable agents missing). And $\underline{S}$ will control all the assets, whatever the control structure. ${ }^{18}$

If we think of the asset(s) as a firm, or project, it would be rather an extreme case if an entire group of agents were literally indispensable. More realistically, we might suppose that there is a group of agents who are key to the success of a project-in the sense that they are

${ }^{17}$ An exception is the case in which only one agent has an action. Then propositions 2 and 6 tell us that it does not matter whether this agent or the indispensable agent has ownership rights.

${ }^{18}$ There is a caveat: $S$ must control all the assets $\underline{A}$. However, we know from proposition 3 and $\alpha(\varnothing)=\varnothing$ that this should indeed be the case. 
particularly skilled or knowledgeable - but it would not be a calamity if a few of them (say less than half) were absent.

Definition. A group $G$ of agents is a key group to an asset $a_{n}$ if more than half of them are needed to generate marginal product from $a_{n}$. That is, for all agents $i$ in any coalition $S$ and for all sets $A$ of assets containing $a_{n}, v^{2}(S, A) \equiv v^{2}\left(S, A \backslash\left\{a_{n}\right\}\right)$ if $S$ contains less than or equal to half of the agents in $G$.

Suppose that a group $G$ is key to an asset. Then consider any coalition $S$ that contains more than half of the agents in $G$. The complementary coalition, $\underline{S} \backslash S$, would have too few members of the key group to benefit from the asset, and so control of it is best not given to them, but instead given to $S$. This suggests a possible explanation for partnerships, where control is decided by majority rule. If each of the members of $G$ is given a vote, the right control structure is ensured: only those coalitions $S$ that contain a majority of $G$ get control over the asset. Hence, we have the following proposition.

Proposition 7. If a group of agents are key to an asset, then control of the asset should be decided by simple majority voting among them.

Next, we turn from grouping agents to the question of grouping assets. There are many examples of assets that ordinarily are owned or controlled together: for example, a window of a house and the house itself, a lock and a key, the engine of a truck and its chassis, a list of clients' names and the list of their addresses, a baseball field and the spectator stand, the two ends of a pipeline, a railroad track and the rolling stock, and power stations and the distribution grid. Why are these assets usually paired together, even though in principle they could be owned or controlled separately?

Definition. Two assets $a_{m}$ and $a_{n}$ are (strictly) complementary if they are unproductive unless they are used together. That is, for all coalitions $S$ and for all sets $A$ of assets containing $a_{m}$ and $a_{n}$,

$$
v^{i}\left(S, A \backslash\left\{a_{m}\right\}\right) \equiv v^{i}\left(S, A \backslash\left\{a_{n}\right\}\right) \equiv v^{i}\left(S, A \backslash\left\{a_{m}, a_{n}\right\}\right) \quad \text { if } i \in S .
$$

Proposition 8. If two (or more) assets are (strictly) complementary, they should be owned or controlled together.

Proof. Suppose that $a_{m}$ and $a_{n}$ are complementary but that under control structure $\alpha$ for some coalition $S, a_{m} \in \alpha(S)$ and $a_{n} \notin \alpha(S)$. Consider a new coalition structure $\hat{\alpha}$, which is the same as $\alpha$ except that whenever any coalition controls $a_{m}$ under $\alpha$, that same coalition controls both $a_{m}$ and $a_{n}$ under $\hat{\alpha}$. It is straightforward to confirm that $\hat{\alpha}$ satisfies requirements (2) and (3).

The change $B_{i}^{i}(\hat{\alpha})-B_{\imath}^{i}(\alpha)$ in marginal return on investment for some agent $i$ will be 


$$
\begin{aligned}
& \sum_{\left.S\right|_{a_{m} \in \alpha(S) ; a_{n} \notin \alpha(S)} ^{i \in S}} p(S)\left[v^{i}\left(S, \alpha(S) \cup\left\{a_{n}\right\}\right)-v^{i}(S, \alpha(S))\right]
\end{aligned}
$$

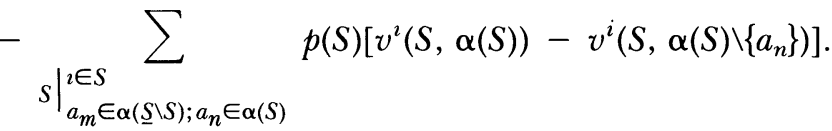

The second summation is zero since $a_{m}$ and $a_{n}$ are complementary. By assumption 6 , the first summation is nonnegative. So agent $i$ 's marginal incentive to invest will not be reduced. Hence by proposition 1 , welfare will be higher under the new control structure $\hat{\alpha}$ than under $\alpha$. Q.E.D.

We saw this result in the second part of the example in the Introduction. Recall the intuition: in order for an agent to derive marginal benefit from either asset, he must be in a coalition that controls both. Separating control of the assets would therefore reduce the number of coalitions, and this would reduce his incentive to invest. ${ }^{19}$

We now consider the opposite extreme of proposition 8. Supposing that there are no synergies between assets, can we conclude that they should be owned or controlled separately? More generally, should ownership extend across agents who are economically independent? And related to this last question, should control be given to an agent who is "dispensable" in the following sense?

Definition. An agent $k$ is dispensable if the other agents' marginal product of investment is unaffected by whether or not he is a member of their coalition (assuming the coalition controls a given set of assets). That is, for all coalitions $S$ containing agent $k$ and for all sets $A$ of assets,

$$
v^{\jmath}(S, A) \equiv v^{\jmath}(S \backslash\{k\}, A) \quad \text { if } j \in S, j \neq k .
$$

We encountered the notion of dispensability in the Introduction (the skipper was dispensable). The idea is that if agent $k$ were not a member of a coalition, the coalition members could hire an outside agent to replace him. At the margin, in this coalition, their individual product of investment would be unchanged. Note that dispensability is equivalent to the existence of a fixed loss associated with having to hire someone who is not as skilled as agent $k$; that is, $v(S, A)=v(S \backslash\{k\}$, $A$ ) $-L$, where $L$ can depend on $x_{k}$, but not on $x_{j}, j \neq k$.

\footnotetext{
${ }^{19}$ Complementarity is related to the notion of increasing returns to scale. Increasing returns implies that two halves of an asset are separately less productive than the whole. Proposition 8 explains why under these conditions it may be desirable for the whole asset to come under common ownership.
} 
Definition. An agent $k$ has some control rights if there is an asset $a_{n}$ and a coalition $S$ containing $k$ such that $a_{n} \in \alpha(S)$ but $a_{n} \notin \alpha(S \backslash\{k\})$.

Proposition 9. An agent who is dispensable and who has no investment should not have any control rights if stochastic control is possible.

Proof. See Appendix A.

An obvious and important corollary of proposition 9 is that outside parties, defined below, should not have any control rights.

Definition. An outside party, agent 0, say, is an agent who is economically independent from the other agents. That is, for any set $A$ of assets and any coalition $S$ not containing agent $0, v(S \cup\{0\}, A) \equiv$ $v(S, A)+v(0)$.

Corollary. An outside party should not have any control rights if stochastic control is possible.

At the intuitive level, this corollary to proposition 9 is compelling: if outside parties have control rights, then the date 1 surplus is shared among a larger set of agents at date 1 . This dilution of the returns on investment serves only to reduce incentives at date 0 . The same argument would seem to apply to anyone who has no investment; but as we know from proposition 6 , if an agent is indispensable, he should be given full control even though he may have no investment. Hence proposition 9 requires not only that an agent has no investment, but also that he is dispensable.

It is perhaps surprising that one cannot rule out control by outside parties without having to resort to stochastic schemes. The reason is that if one is forced to use a deterministic control structure, then outside parties can play a useful role in dividing up ownership. For example, if there are just two agents, 1 and 2 , in $\underline{S}$, then by introducing an outside party and (say) majority rule among the three of them, agents 1 and 2 can be given more balanced incentives than if one of them owns. However, a stochastic control structure in which ownership is randomly allocated between 1 and 2 will be better because it avoids the dissipation of surplus at date $1 .^{20}$

${ }^{20}$ Consider a symmetric case in which agents 1 and 2 work with a single asset, $\underline{A}=$ $\{a\}$. Assume that the asset is essential to both agents (in the sense that their marginal product of investment is zero if they do not have access to it) but that they are both dispensable. Without the introduction of an outside party, there is in effect only one kind of deterministic control structure possible; namely, one of them owns the asset. Let this be agent 1 . Then their marginal returns on investment are, respectively, $v^{1}(\underline{S}$, $\underline{A})$ and $1 / 2 v^{2}(\underline{S}, \underline{A})$. Now it may be that $1 / 2 v^{2}(\underline{S}, \underline{A})$ provides agent 2 with too low an incentive to invest. A control structure that instead uses majority rule among $\{0,1,2\}$, where 0 is an outside party, changes their marginal returns to $2 / 3 v^{1}(\underline{S}, \underline{A})$ and $2 / 3 v^{2}(\underline{S}$, $\underline{A})$. However, a stochastic control structure will do better: e.g., a 50:50 allocation of the asset at date 1 will raise their marginal returns to $3 / 4 v^{1}(\underline{S}, \underline{A})$ and $3 / 4 v^{2}(\underline{S}, \underline{A})$.

One can show that, even if stochastic control is ruled out, an outside party should not 
Proposition 9 implies that ownership should not extend across agents who are economically independent; and if there are no synergies between assets, they should not be owned or controlled together. Owing to the importance of this result, we have written it out as a separate proposition 10. It is a direct application of proposition 9, so no separate proof is needed.

In what follows, assume that $\underline{\hat{S}}$ and $\underline{\hat{S}}$ are disjoint and that $\underline{\hat{A}}$ and $\underline{\hat{A}}$ are disjoint.

Definition. $(\underline{\hat{S}}, \underline{\hat{A}})$ and $(\underline{\hat{S}}, \underline{\hat{\hat{A}}})$ are economically independent if for all coalitions $\hat{\hat{S}}$, $\hat{\hat{S}}$, where $\hat{S} \subseteq \underline{\hat{S}}, \hat{\hat{S}} \subseteq \underline{\hat{S}}$, and for all sets $\hat{A}, \hat{\hat{A}}$ of assets, where $\hat{A} \subseteq \underline{\hat{A}}, \hat{\hat{A}} \subseteq \underline{\hat{A}}$,

$$
v^{2}(\hat{S} \cup \hat{\hat{S}}, \hat{A} \cup \hat{\hat{A}}) \equiv v^{2}(\hat{S}, \hat{A}) \quad \text { if } i \in \hat{S}
$$

and

$$
v^{2}(\hat{S} \cup \hat{\hat{S}}, \hat{A} \cup \hat{\hat{A}}) \equiv v^{2}(\hat{\hat{S}}, \hat{\hat{A}}) \quad \text { if } i \in \hat{\hat{S}}
$$

Definition. $(\underline{\hat{S}}, \underline{\hat{A}})$ and $(\underline{\hat{S}}, \underline{\hat{A}})$ exhibit independent control if no agent in $\underline{\hat{S}}$ has control rights over any of the assets in $\underline{\hat{A}}$, and no agent in $\underline{\hat{S}}$ has control rights over any of the assets in $\underline{\hat{A}}$.

Proposition 10. With economic independence there should be independent control. ${ }^{21}$

Finally in this section, we consider the effect of a change in ownership on an agent who works with an asset that is essential to him, for example, a worker at a firm. The important point is that, outside the firm, the worker's specific investment is unproductive.

Definition. An asset $a_{n}$ is essential to an agent $i$ if the marginal product of investment for the agents in a coalition will not be enhanced by agent $i$ unless the coalition controls $a_{n}$. That is, for all agents $j$ in any coalition $S$ and for all sets $A$ of assets, $v^{J}(S, A) \equiv$ $v^{\jmath}(S \backslash\{i\}, A)$ if $a_{n} \notin A$.

Notice that, in the light of assumption 3 , the definition implies that for agent $i$ himself (i.e., for $j=i$ ), $v^{i}(S, A) \equiv 0$ if $a_{n} \notin A .^{22}$

Proposition 11. Suppose that an agent with an investment has an essential asset that is owned by a second agent. Then if we ignore the effects of changes in other agents' investment levels, the first agent's

be the sole owner of an asset that is "essential" to another agent; see the definition of an essential asset before proposition 11 .

${ }^{21}$ If stochastic control is ruled out, then proposition 10 would require that the two groups $\underline{\hat{S}}$ and $\underline{\hat{S}}$ each have access to outside parties for the purpose of dividing ownership.

${ }^{22}$ Strictly speaking, proposition 11 requires only that $v^{2}(S, A) \equiv 0$ if $a_{n} \notin A$. However, the full definition of an essential asset is used elsewhere in the paper. 
incentive to invest will be increased if the second agent takes ownership of all the assets.

\section{Proof. See Appendix A.}

The intuition behind this result is that if an asset $a_{n}$ is essential to an agent $i$ but another agent $j$ owns it, then $i$ 's marginal return on investment will be zero unless he is in a coalition with $j$. Given that $j$ owns $a_{n}$, $i$ 's incentive to invest will be highest if $j$ owns all the other assets too, because that way $i$ will have access to all those assets whenever his investment is productive, and at the margin this will enable him to strengthen his bargaining position at date 1 .

Proposition 11 can help us to rule out rather strange control structures; for example, agent $i$ owns an asset $a$ that is essential to a group of workers, $\{w\}$, but at the same time an agent $j$ owns an asset $a^{*}$ that is essential to agent $i$. This corresponds to a hybrid employment structure in which workers are employed at one firm, while the boss of that firm is working for another firm.

Proposition 11 suggests that it may be better to gather the two assets under common ownership. Specifically, the control structure should be arranged so as to have only one boss-agent $j$-at the top of a single firm $\left\{a, a^{*}\right\}$. However, there would be a drawback to this arrangement if, for example, agent $i$ were indispensable, because then under the new ownership structure the workers $\{w\}$ could be productive only in a coalition that contained both $i$ and $j$. If $i$ is dispensable, then this drawback disappears, and as shown in the following proposition, we can rule out the hybrid arrangement.

Proposition 12. Suppose that an asset $a$ is essential to a group of workers $\{w\}$ and an asset $a^{*}$ is essential to an agent $i$, who is dispensable. Then if we ignore the effects of changes in investment by parties other than $i, j$, and $\{w\}$, agent $i$ should not own $a$ if $a^{*}$ is owned by some other agent $j$.

\section{Proof. See Appendix A. ${ }^{23}$}

${ }^{23}$ It is appropriate at this point to note that the results of this section generalize to divisions of surplus other than the Shapley value, in particular, the Banzhaf-Coleman index, where $p(S)$ in (4) is replaced by $2^{1-n}$ (see Owen 1982, sec. 10.3); the weighted Shapley value, where the constants $p(S)$ reflect the bargaining abilities of the members of $S$ (Kalai and Samet 1988); and Kalai and Samet's egalitarian solution, which for games with transferable utility, as here, reduces to a particular weighted Shapley value (Kalai and Samet 1985).

It is of interest to state general conditions under which our results hold. Denote by $B_{i}$ agent $i$ 's share of total surplus, which will in general be a function of the entire vector of values $\{v(S) \mid S \subseteq S\}$ and also a function of $x$. Then propositions $1-8$ and 11 are true as long as, in addition to assumptions $1-6$, (i) $B_{i}$ is concave in $x$, (ii) $B_{i}$ is weakly increasing in $v(S)$ for all $S$ containing $i$, and (iii) $\partial B_{i} / \partial v(S)$ is weakly increasing in $v\left(S^{\prime}\right)$ for all $S$ containing $i$ and for all $S^{\prime}$. (Propositions 9, 10, and 12 require a little more: a mild symmetry condition on the division of surplus would suffice.) Notice that condition $i$ is a natural extension of assumption 2, condition ii is weak and very natural, but condition iii is strong and certainly will not always be satisfied. See the discussion in Sec. V. 


\section{Applications}

We now apply and develop the results from the previous section. We begin with the case of a single asset.

\section{A. One Asset}

Suppose that $J$ workers, $w 1, \ldots, w J$, work with a single asset, $a$, to supply a service to $K$ consumers, $c 1, \ldots, c K$. For simplicity assume that the asset is essential to the workers in the sense of Section III and that only they have investment decisions. Who should have ownership rights over the asset?

We have seen in Section III that an individual is more likely to have ownership rights if his investment is important or if he is an important (in the limit, an indispensable) trading partner. Specifically, if only one of the workers has an investment or one of the consumers, say, is indispensable, then that one should be the owner or boss (propositions 2 and 6). More generally, if there is a group $G$ of "key" agents such that for any worker's marginal product of investment to be positive he must be a member of a coalition containing a majority of members of $G$ (different majorities may do for different workers), then it is optimal to give each member of $G$ a vote and to adopt majority rule (proposition 7). Such an arrangement can be interpreted as a partnership if $G$ is a subset of $\{w 1, \ldots, w J\}$, as a worker cooperative if $G=\{w 1, \ldots, w J\}$ (i.e., a majority of all workers is required to realize a positive marginal product of investment), and as a consumer cooperative if $G=\{c 1, \ldots, c K\}$.

To get some insight into the case in which there is no group of key agents, consider the opposite extreme in which every agent is dispensable. According to proposition 9, ownership rights should then be allocated over those agents that invest. Denote this subset by $H$. Since everyone is dispensable, $v^{i}(S,\{a\})=v^{i}(\underline{S},\{a\})$ for all $i$ in any coalition $S$ $\cap H$, where $\underline{S}$ is the coalition of all agents. So the first-order condition (FOC) (5) for agent $i$ 's investment $x_{i}$ simplifies to $p_{i} v^{i}(\underline{S},\{a\})=C_{i}^{\prime}\left(x_{i}\right)$, where, from our discussion of the Shapley value in Section II, $p_{i}$ is the probability that $i$ belongs to a coalition that owns $a$. Propositions 3 and 9 together imply that it is optimal for every subset of $H$ or its complement to control $a$ (if the control structure is stochastic, this last condition holds for all realizations of the control structure). From this it follows that

$$
\sum_{i \in H} p_{i}=1 / 2+1 / 2|H|
$$


for an optimal control structure. ${ }^{24}$ Thus if every agent is dispensable, an optimal control structure amounts to an allocation of the $p_{i}$ 's subject to the constraint (6).

We can say more about the ownership structure when every agent is dispensable in two special cases. First, if there is symmetry within the group $H$, that is, each agent's investment has the same importance, we might expect the optimum to have $p_{i}=1 / 2+1 /(2|H|)$ for all $i$ in $H$. It is interesting to note that if $|H|$ is odd, this can be achieved by giving each member of $H$ a vote and adopting majority rule.

Second, suppose that there is one "big" worker and many "small" workers, in the sense that the big worker's investment is an order of magnitude more important than a small worker's (i.e., the social value of a dollar increase in the big worker's investment is comparable to the social value of a simultaneous dollar increase in all the small workers' investments). Then the analysis above tells us that the big worker should have all the control rights. (We are retaining the assumption that everyone is dispensable, but it is easy to see that what follows continues to hold if the big worker is not dispensable.) The reason is that, according to (6), it is impossible to allocate control rights to the small workers so as to yield $p_{i}$ 's significantly above $1 / 2$ for more than a small fraction of them. But this means that their aggregate investment will hardly differ from what it would be if the big worker were made sole owner and $p_{i}=1 / 2$ for each small worker. On the other hand, the big worker's investment will be strictly higher if he is the owner. Hence, giving all control rights to the big worker will be optimal in such a situation.

In general, we expect to find something in between the extremes in which either there is a key group of agents that everyone needs to trade with or agents are dispensable. Rather than analyzing this general situation, however, we turn to a model with two assets.

\section{B. Two Assets}

Consider now a situation in which there are two assets, $a_{1}$ and $a_{2}$, and assume that for each asset there are workers to whom the asset is essential. One can imagine that the workers of asset $a_{1}$ use $a_{1}$ to supply some service to the workers of asset $a_{2}$, who then use it together with $a_{2}$ to produce a final good for consumers. For simplicity we do not

${ }^{24}$ To see this, consider any random ordering (e.g., $\left.\{3,1,2,5,4\}\right)$ of members of $H$ and let $\xi_{i}=1$ if $i$ belongs to a coalition that controls $a$ and $\xi_{i}=0$ otherwise. Now reverse the ordering (to obtain $\{4,5,2,1,3\}$ ) and denote the new $\xi_{i}$ 's by $\hat{\xi}_{i}$. Then it is easy to show that $\Sigma_{i \in H} \xi_{i}+\Sigma_{i \in H} \hat{\xi}_{i}=|H|+1$. Taking the expectation over all orderings and their reverses yields (6). 
explicitly model final consumers (or any other input suppliers); one can suppose that the good is sold (and other inputs are purchased) on a spot market.

To simplify further, we shall suppose that each asset $a_{i}, i=1,2$, has one big worker $i$ and many small workers $\{w i\}$, in the sense of subsection $A$ above, where each small worker is dispensable. (To avoid heavy notation, we simply give the small workers the generic description $w 1$ or $w 2$; there is no presumption that they are identical.) Under these conditions, we know that it will not be optimal to give the small workers control rights.

Hence the issue is whether (i) $a_{1}$ should be owned by 1 and $a_{2}$ should be owned by 2 (which can be interpreted as nonintegration, with 1 as the boss of the first firm and 2 as the boss of the second firm); (ii) 1 should own both assets (integration with 1 as boss of the integrated firm); or (iii) 2 should own both assets (integration with 2 as boss). Actually, there is a fourth possibility: (iv) 1 owns $a_{2}$ and 2 owns $a_{1}$. We shall show at the end of this subsection that this is not optimal.

We start with possibilities i and ii and write the FOCs for the agents' investment levels. Bearing in mind that the workers $w 1$ and $w 2$ are dispensable, we can simplify notation and omit reference to them in the coalitions of agents. For example, $v^{1}\left(12,\left\{a_{1}, a_{2}\right\}\right)$ equals l's marginal product of investment in any coalitions $\{1,2\} \cup S_{1} \cup S_{2}$ that control assets $a_{1}$ and $a_{2}$, where $S_{1}$ and $S_{2}$ are, respectively, arbitrary sets of workers $w 1$ and $w 2$. Also, $v^{w 1}\left(1,\left\{a_{1}\right\}\right)$ equals a certain worker $w 1$ 's marginal product of investment in coalitions $\{1\} \cup S_{1} \cup S_{2}$ that control asset $a_{1}$, where now $S_{1}$ must contain this particular worker.

i. Nonintegration: 1 Owns $a_{1}, 2$ Owns $a_{2}$

FOC for 1 :

$$
1 / 2 v^{1}\left(12,\left\{a_{1}, a_{2}\right\}\right)+1 / 2 v^{1}\left(1,\left\{a_{1}\right\}\right)=C_{1}^{\prime}\left(x_{1}\right) .
$$

FOC for typical $w 1$ :

$$
1 / 3 v^{w 1}\left(12,\left\{a_{1}, a_{2}\right\}\right)+1 / 6 v^{w 1}\left(1,\left\{a_{1}\right\}\right)=C_{w 1}^{\prime}\left(x_{w 1}\right) .
$$

FOC for 2:

$$
1 / 2 v^{2}\left(12,\left\{a_{1}, a_{2}\right\}\right)+1 / 2 v^{2}\left(2,\left\{a_{2}\right\}\right)=C_{2}^{\prime}\left(x_{2}\right) .
$$

FOC for typical $w 2$ :

$$
1 / 3 v^{w 2}\left(12,\left\{a_{1}, a_{2}\right\}\right)+1 / 6 v^{w 2}\left(2,\left\{a_{2}\right\}\right)=C_{w 2}^{\prime}\left(x_{w 2}\right) .
$$


ii. Integration: 1 Owns $a_{1}$ and $a_{2}$

FOC for 1:

$$
1 / 2 v^{1}\left(12,\left\{a_{1}, a_{2}\right\}\right)+1 / 2 v^{1}\left(1,\left\{a_{1}, a_{2}\right\}\right)=C_{1}^{\prime}\left(x_{1}\right) .
$$

FOC for typical $w 1$ :

$$
1 / 3 v^{w 1}\left(12,\left\{a_{1}, a_{2}\right\}\right)+1 / 6 v^{w 1}\left(1,\left\{a_{1}, a_{2}\right\}\right)=C_{u u^{\prime}}^{\prime}\left(x_{u^{\prime}}\right) .
$$

FOC for 2:

$$
1 / 2 v^{2}\left(12,\left\{a_{1}, a_{2}\right\}\right)=C_{2}^{\prime}\left(x_{2}\right) .
$$

FOC for typical $w 2$ :

$$
1 / 3 v^{w 2}\left(12,\left\{a_{1}, a_{2}\right\}\right)+1 / 6 v^{w 2}\left(1,\left\{a_{1}, a_{2}\right\}\right)=C_{w 2}^{\prime}\left(x_{w 2}\right) .
$$

We now use these conditions ${ }^{25}$ to compare the marginal incentive to invest under nonintegration and integration, for each agent in turn.

Not surprisingly, comparing (7e) with (7a), we see that agent 1 has a greater incentive to invest under integration since he then always has access to both assets. Correspondingly, comparing (7c) with (7g), we see that agent 2 has a greater incentive to invest under nonintegration since he then always has access to $a_{2}$.

What is more interesting is the effect of integration on the employees $\{w 1\}$ and $\{w 2\}$. Comparing (7f) with (7b), we see that, ignoring the effects of changes in the other agents' investment levels, a typical $w 1$ 's incentive to invest is unambiguously greater under integration (proposition 11). The reason is that under either nonintegration or integration, $w 1$ has to be in a coalition with 1 to be productive at the margin since, by assumption, he requires access to $a_{1}$. But under integration, every time he is in a coalition with 1 , he also has access to $a_{2}$ and is therefore more productive.

The situation for a typical $w 2$ is less clear since, in contrast to $w 1$, his boss 2 loses control when switching to integration. On the positive side, $w 2$ is more likely to have access to both assets since this will

${ }^{25}$ To understand these conditions, it may be worth recapping the "random ordering" explanation of the Shapley value that we gave in Sec. II. Consider the case of nonintegration. With probability $1 / 2$, agent 1 appears before 2 in the random ordering at date 1 and receives his full marginal product $v^{1}\left(12,\left\{a_{1}, a_{2}\right\}\right)$. With probability $1 / 2$, he appears after 2 , in which case he receives $v^{1}\left(1,\left\{a_{1}\right\}\right)$-bearing in mind that he owns $a_{1}$ but not $a_{2}$. This explains (7a). In contrast, a worker $w 1$ has a positive marginal product only if he appears before 1 in the random ordering (otherwise he is in a coalition that does not have access to his essential asset $\left.a_{1}\right)$. With probability $1 / 3$, he is before 1 and 2 , in which case he receives $v^{w 1}\left(12,\left\{a_{1}, a_{2}\right\}\right)$. With probability $1 / 6$, he is before 1 but after 2 , in which case he receives $v^{w 1}\left(1,\left\{a_{1}\right\}\right)$. This explains $(7 \mathrm{~b})$. (The missing terms are $1 / 6 v^{w 1}(2$, $\left.\left\{a_{2}\right\}\right)$ and $1 / 3 v^{w 1}(\varnothing, \varnothing)$, which are both zero.) The six other conditions $(7 \mathrm{c})-(7 \mathrm{~h})$ follow similarly. 
happen whenever he is in a coalition with his new boss 1 ; previously he had to be in a coalition with both 1 and 2 for this to occur. On the negative side, under integration, $w 2$ is less likely to find himself in a coalition with his old boss 2 and asset $a_{2}$; if this is a powerful combination, it can cause a loss. For example, if 2 is indispensable to $a_{2}$ (implying $\left.v^{w 2}\left(1,\left\{a_{1}, a_{2}\right\}\right)=0\right)$, a comparison of (7h) with (7d) shows that $w 2$ 's incentive to invest falls under integration. (We know from proposition 6 that if agent 2 is indispensable to an asset, then he should own it, which means that it cannot be optimal for 1 to acquire $a_{2}$.)

To summarize, there are two effects from integration on employees. On the one hand, there is a positive effect due to increased coordination: agents now have to negotiate with only one person to get access to both assets. (This positive effect also applies to the boss of the acquiring firm: he does not now have to bargain with anyone to get access to both assets.) On the other hand, there is a negative effect due to the fact that an employee of the acquired firm now has to negotiate with two people to have access to both his essential asset and his old boss. (This negative effect also applies to the boss of the acquired firm.)

In some special cases, we can say which effect will dominate. First, if 2 is dispensable, the negative effect on the employee $w 2$ disappears: ${ }^{26}$ $v^{w 2}\left(1,\left\{a_{1}, a_{2}\right\}\right) \geq v^{w 2}\left(2,\left\{a_{2}\right\}\right)$. In this case, then, the only cost of integration is the negative incentive effect on agent 2 .

Second, if assets $a_{1}$ and $a_{2}$ are economically independent in the sense that $v^{i}\left(S_{1} \cup S_{2},\left\{a_{1}, a_{2}\right\}\right)=v^{i}\left(S_{1},\left\{a_{1}\right\}\right)$ for all $i \in S_{1}$ and $v^{i}\left(S_{1} \cup S_{2},\left\{a_{1}\right.\right.$, $\left.\left.a_{2}\right\}\right)=v^{i}\left(S_{2},\left\{a_{2}\right\}\right)$ for all $i \in S_{2}$ - where $S_{1}$ and $S_{2}$ are any subcoalitions of $\{1+$ workers $w 1\}$ and $\{2+$ workers $w 2\}$, respectively-then nonintegration always dominates integration (proposition 10). (The FOCs [7a], [7b], [7e], and [7f] imply that the incentives of 1 and $w 1$ are unchanged under integration, while $[7 \mathrm{c}],[7 \mathrm{~d}],[7 \mathrm{~g}]$, and $[7 \mathrm{~h}]$ imply that the incentives of 2 and $w 2$ are reduced.) This simply reflects the fact that in the absence of a synergy between assets $a_{1}$ and $a_{2}$, making 1 the owner of asset $a_{2}$ is like bringing in an outside party: its only effect is to dilute incentives (proposition 9).

Third, if assets $a_{1}$ and $a_{2}$ are (strictly) complementary in the sense that $v^{i}\left(S,\left\{a_{1}\right\}\right)=v^{i}\left\{S,\left\{a_{2}\right\}\right)=v^{i}(S, \varnothing)=0$ for all $i$ in any coalition $S$, then integration always dominates nonintegration (proposition 8). This follows from the fact that $v^{2}\left(2,\left\{a_{2}\right\}\right)$ and $v^{w 2}\left(2,\left\{a_{2}\right\}\right)$ are both zero in $(7 \mathrm{c})$ and $(7 \mathrm{~d})$, and hence the negative incentive effects of integration on 2

${ }^{26}$ This is similar to the effect in proposition 12. Recall that, in the context of that proposition, an asset $a\left(\equiv a_{2}\right)$ is essential to an agent $w(\equiv w 2)$. The agent's incentive to invest does not fall when agent $j(\equiv 1)$ takes over the ownership of $a$ from agent $i(\equiv 2)$, given that agent $i$ is dispensable. 
and $w 2$ disappear. In words, suppose that two assets are (at the margin) useless unless used together, but they are owned by two different people. Then making one of these people the owner of both assets will help outside agents, who now have to negotiate with only one person rather than two people in order to use them. (And of course the owner himself can now use both assets without having to negotiate with anyone else.) The person who used to own one of the assets does not lose out since he could not use the asset without reaching an agreement with the other person anyway. Of course, this argument does not tell us that 1 should be the owner rather than 2; it says only that the assets should be under common ownership.

Once we leave these special cases, the costs and benefits are less easy to evaluate. The main forces are summarized in table 1.

As noted before, there are two other cases to consider: (iii) 2 can own both assets or (iv) 1 owns $a_{2}$ and 2 owns $a_{1}$ ("reverse" nonintegration). Obviously, considerations similar to those above determine when it is better to concentrate both assets in 2's hands than to have them separately owned. The choice of making either 2 or 1 the owner of both assets will be determined by factors such as who has the more important investment or who is the less dispensable. Finally, it is easy to show that reverse nonintegration is never optimal; it is dominated by making 1 the owner of both assets. This follows from the fact that ownership by 1 will raise the incentives of 1 and the workers $w 1$ and cannot lower the incentives of 2 and the workers $w 2$ since these agents had to reach agreement with 1 anyway to have access to $a_{2}$.

\section{Three Assets}

New effects arise when there are more than two assets. We do not have space to be comprehensive, but we would like to discuss briefly the effects on a third firm of two firms' merging.

To simplify, we ignore employees now and suppose that each of the three assets $\left\{a_{1}, a_{2}, a_{3}\right\}$ has just one (big) agent working on it: agents 1 , 2 , and 3 , respectively. As above, asset $a_{i}$ is assumed to be essential for agent $i$. We further simplify by assuming that all three agents are dispensable. As a final simplification, in this subsection we consider only control structures $\alpha$ in which each asset has a sole owner. In the following subsection, we shall briefly discuss multiple ownership in a model that has more assets.

The first finding is that if an agent does not own the asset that is essential to him, then he should not own any other asset. To see why, note that such an arrangement would be equivalent to one of the following (subject to relabeling): 2 owns $a_{1}$ and 3 owns $a_{2}$, or 2 owns $a_{1}$ and 1 owns $a_{2}$. Both arrangements would be dominated by having 3 


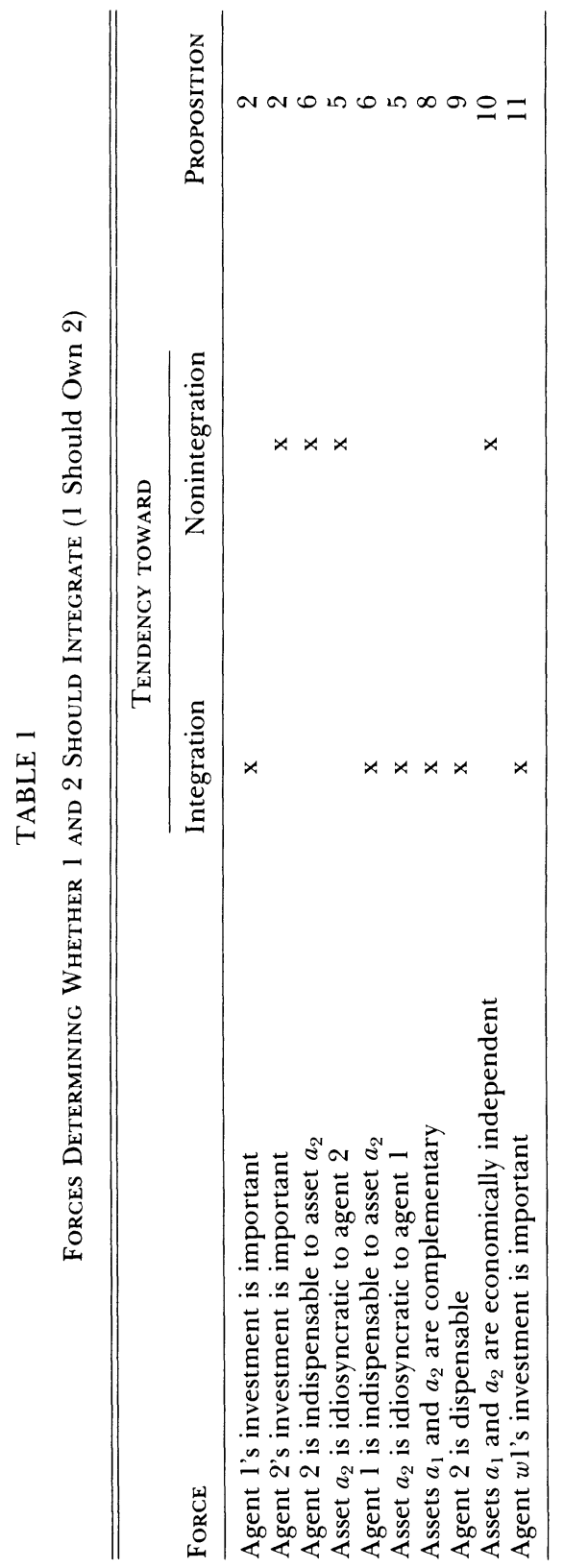


owning $a_{1}, a_{2}$, and $a_{3}$ (he may already own $a_{3}$ ): obviously 3 's incentive to invest would increase, but so too would 1's and 2's since each had to be in a coalition with one other person to be productive anyway. In fact we know from proposition 12 that the first arrangement is not optimal, given that 2 is dispensable.

This leaves us with three possibilities (subject to relabeling): (i) nonintegration ( 1 owns $a_{1}, 2$ owns $a_{2}$, and 3 owns $a_{3}$ ), (ii) partial integration (1 owns $a_{1}$ and $a_{2}$, and 3 owns $a_{3}$ ), and (iii) integration (1 owns $a_{1}, a_{2}$, and $\left.a_{3}\right)$.

Partial integration is the distinctive new control structure in a threeasset model. The main new effect is that if 1 acquires $a_{2}$, then this has an impact on 3. So how are 3's incentives affected by a change from nonintegration to partial integration? The FOCs for 3's choice of investment $x_{3}$ in these two cases are written out below. Since all three agents are dispensable, we can omit reference to the coalitions in the marginal products, $v^{i}$, and simply write, say, $\underline{v}^{3}\left(a_{1}, a_{2}, a_{3}\right)$ for any one of $v^{3}\left(3,\left\{a_{1}, a_{2}, a_{3}\right\}\right), v^{3}\left(13,\left\{a_{1}, a_{2}, a_{3}\right\}\right), v^{3}\left(23,\left\{a_{1}, a_{2}, a_{3}\right\}\right)$, or $v^{3}\left(123,\left\{a_{1}\right.\right.$, $\left.a_{2}, a_{3}\right\}$ ).

\section{i. Nonintegration}

FOC for 3:

$$
1 / 3 \underline{v}^{3}\left(a_{1}, a_{2}, a_{3}\right)+1 / 6 \underline{v}^{3}\left(a_{1}, a_{3}\right)+1 / 6 \underline{v}^{3}\left(a_{2}, a_{3}\right)+1 / 3 \underline{v}^{3}\left(a_{3}\right)=C_{3}^{\prime}\left(x_{3}\right) .
$$

\section{ii. Partial Integration}

FOC for 3:

$$
1 / 2 \underline{v}^{3}\left(a_{1}, a_{2}, a_{3}\right)+1 / 2 \underline{v}^{3}\left(a_{3}\right)=C_{3}^{\prime}\left(x_{3}\right) .
$$

Thus if we ignore the effects of changes in the other agents' investment levels, agent 3 will have a greater incentive to invest under partial integration than under nonintegration, provided that

$$
\underline{v}^{3}\left(a_{1}, a_{2}, a_{3}\right)+\underline{v}^{3}\left(a_{3}\right)>\underline{v}^{3}\left(a_{1}, a_{3}\right)+\underline{v}^{3}\left(a_{2}, a_{3}\right) \text {. }
$$

A sufficient condition for (8) to hold is that 1 and 3 obtain limited synergy in the absence of 2 , or that 2 and 3 obtain limited synergy in the absence of 1 . In the first case (in approximate terms),

$$
\begin{aligned}
v\left(13,\left\{a_{1}, a_{3}\right\}\right)=v\left(1,\left\{a_{1}\right\}\right)+v\left(3,\left\{a_{3}\right\}\right) & \Rightarrow \underline{v}^{3}\left(a_{1}, a_{3}\right)=\underline{v}^{3}\left(a_{3}\right) \\
& \Rightarrow(8) \text { holds. }
\end{aligned}
$$

In the second case (in approximate terms), 


$$
\begin{aligned}
v\left(23,\left\{a_{2}, a_{3}\right\}\right)=v\left(2,\left\{a_{2}\right\}\right)+v\left(3,\left\{a_{3}\right\}\right) & \Rightarrow \underline{v}^{3}\left(a_{2}, a_{3}\right)=\underline{v}^{3}\left(a_{3}\right) \\
& \Rightarrow(8) \text { holds. }
\end{aligned}
$$

There are, however, circumstances in which agent 3 will have a greater incentive to invest under nonintegration than under partial integration. If the assets $a_{1}$ and $a_{2}$ are close substitutes-in the sense that the main synergies occur between 1 and 3 or 2 and 3 - then $v^{3}\left(a_{1}\right.$, $\left.a_{2}, a_{3}\right)$ is likely to be close to both $\underline{v}^{3}\left(a_{1}, a_{3}\right)$ and $\underline{v}^{3}\left(a_{2}, a_{3}\right)$, and (8) will not hold. Here, 3's incentives are greater when $a_{1}$ and $a_{2}$ are separately owned, so that their owners 1 and 2 have to compete with each other for access to his asset $a_{3}$. That is, as one might expect, if two competing traders merge, this will worsen the incentives of the owner-manager of a firm that trades with them.

\section{Many Assets}

In subsection $C$, we focused on the case in which each of the (three) assets had a single owner. In order to obtain some insight into the circumstances in which multiple ownership will be selected, consider the following.

There are $N$ assets (firms), $\underline{A}=\left\{a_{1}, \ldots, a_{N}\right\}$, and $N$ agents, $\underline{S}=\{1$, $\ldots, N\}$. We make the standard assumption that asset $a_{i}$ is essential to agent $i$. We also assume that all the agents are dispensable.

Agent 1 uses $a_{1}$ to supply firms $a_{2}, \ldots, a_{N}$. The particular interpretation that we have in mind is that $a_{1}$ is an oil pipeline and $a_{2}, \ldots, a_{N}$ are oil refineries (this case is discussed in Klein et al. [1978]). A fairly natural assumption to make then is that the only synergies are bilateral, between $a_{1}$ and each of $a_{2}, \ldots, a_{N}$. Note that $a_{2}, \ldots, a_{N}$ are useless in the absence of $a_{1}$. Thus for all $i \neq 1$ in any coalition $S$ and for all sets $A$ of assets, we are assuming that

$$
\begin{aligned}
v^{\imath}(S, A) & =v^{2}\left(\underline{S},\left\{a_{1}, a_{i}\right\}\right) & & \text { if } a_{1}, a_{i} \in A \\
& =0 & & \text { otherwise. }
\end{aligned}
$$

(Note the implicit assumption that there is no capacity constraint in the pipeline.)

Since $a_{2}, \ldots, a_{N}$ are useless without $a_{1}$, we expect some common ownership to be optimal here. If l's investment is particularly important, there is a case for 1 owning all the assets (integration downstream). On the other hand, if l's investmęnt can be ignored but those of $2, \ldots, N$ are important (as is arguably the case in the pipeline example), then $2, \ldots, N$ will share control rights in $a_{1}$ (proposition 9).

Suppose that 1's investment $x_{1}$ can be ignored. Given our assumptions, agent $i$ 's FOC for his investment $x_{i}$ is 


$$
p_{\imath} v^{\imath}\left(\underline{S},\left\{a_{1}, a_{\imath}\right\}\right)=C_{\imath}^{\prime}\left(x_{\imath}\right) \text { for } 2 \leq i \leq N,
$$

where $p_{\imath}$ is the probability that $i$ belongs to a coalition that owns $a_{1}$. Now, as in (6),

$$
\sum_{i=2}^{N} p_{\imath}=1 / 2 N .
$$

Hence an optimal control structure amounts to an allocation of the $p_{\imath}$ 's across the agents $2, \ldots, N$, in accordance with the responsiveness and importance of their investments, subject to (9). One way to achieve such an allocation is to give (not necessarily equal) shares or votes in $a_{1}$ to each agent $2, \ldots, N$ and adopt simple majority rule (this guarantees that proposition 3 holds); obviously, an agent's $p_{\imath}$ will be increasing in the number of votes he receives.

Arrangements like these are in fact observed in the case of oil pipelines, with an agent's share being linked to his use of the pipeline. ${ }^{27}$ To the extent that usage is in turn related to investment, this finding is consistent with the model presented here. ${ }^{28}$

The multiasset analysis can be extended in several ways. First, the assumption of dispensability can be dropped. In the example just discussed, this would have the consequence that allocating control rights in $a_{1}$ to agent $i$ rather than agent 1 will have a negative effect on $j$ 's incentives to the extent that access to agent 1 as well as asset 1 is important for $j$. Second, the assumption that there is only one agent per asset can be relaxed. We leave such generalizations for future work.

\section{Concluding Remarks}

In this paper, we have developed a theory of the optimal assignment of assets and used it to understand the boundaries of the firm. We have shown that an agent is more likely to own an asset if his action is sensitive to whether he has access to the asset and is important in the generation of surplus, or if he is a crucial trading partner for others whose actions are sensitive to whether they have access to the asset and are important in the generation of surplus. In addition, if one starts from a situation in which some agent 1 owns an asset $a_{1}$ worked on by workers $\{w 1\}$ and some agent 2 owns an asset $a_{2}$ worked on by workers $\{w 2\}$, a move to common ownership of both assets by agent 1

\footnotetext{
${ }^{27}$ See Klein et al. (1978). In practice, the owners of the pipeline include oil wells as well as oil refineries; it would be easy to extend the analysis above to allow some of the $a_{t}$ to stand for oil wells.

${ }^{28}$ These ideas might also be applied to the case of joint ownership of bridges by different railroads in the nineteenth century (see Chandler 1977, p. 124).
} 
is likely to increase overall efficiency to the extent that (i) the assets are strongly complementary, (ii) 1 is an important trading partner for 2 and the workers $\{w 2\}$, (iii) 2 is dispensable or his investment is not particularly important, and (iv) 1 has an important investment or the workers $\{w 1\}$ have important investments (in aggregate). On the other hand, common ownership is likely to decrease overall efficiency to the extent that (i) the assets are economically independent, (ii) 2 is an important trading partner for the workers $\{w 2\}$, (iii) l's investment is not particularly important, and (iv) 2 has an important investment or the asset $a_{2}$ is idiosyncratic to him.

An important idea underlying the analysis is that a key right provided by ownership is the ability to exclude people from the use of assets. We have argued that this authority over assets translates into authority over people: an employee will tend to act in the interest of his boss. Although we have emphasized the role of tangible assets such as machines (or inventories), location, or client lists, we suspect that the ideas may generalize to intangible assets such as goodwill. Some nonhuman assets are essential for the argument, however, and in fact we suspect that they are an important ingredient of any theory of the firm. The reason is that in the absence of any nonhuman assets, it is unclear what authority or control means. Authority over what? Control over what? Surely integration does not give a boss direct control over workers' human capital, in the absence of slavery. ${ }^{29}$

An important assumption that we have made is that the gains from bargaining are divided according to the Shapley value. This is obviously strong, but we do not believe that the assumption is crucial for

${ }^{29}$ For a more extensive discussion of the notion of authority, see O. Hart (1989). This view of physical assets and authority can shed light on the well-known criticism that Alchian and Demsetz (1972) made of Coase's (1937) paper. Coase argued that the key difference between an employer-employee relationship and one between independent contractors is that whereas an employer can tell an employee what to do, one independent contractor must persuade another independent contractor to do what he wants through the use of prices (see also Simon 1951; Arrow 1974). Alchian and Demsetz pointed out that an employer typically cannot force an employee to do what he wants: he can only ask him and fire the employee if he refuses. However, this is no different from one independent contractor's firing another (quitting their relationship) if he is unhappy with the latter's performance (an employer can "fire or sue, just as I can fire my grocer by stopping purchases from him or sue him for delivering faulty products" [Alchian and Demsetz 1972, p. 777]). Our approach reconciles these two positions. While it follows Alchian and Demsetz in not distinguishing between the contractual form or nature of sanctions in the two relationships, it captures the idea that one agent is more likely to do what another agent wants if they are in an employment relationship than if they are independent contractors. The reason the manager of Alchian and Demsetz's grocery store will be more likely to follow their wishes if they employ him than if they are customers is that in the former case his future livelihood depends on them (they control the assets the manager intends to work with), whereas in the latter case it does not. 
our results. Two observations support this. First, we have mentioned a number of immediate extensions of our analysis in note 23. Second, the example in the Introduction makes clear that, in the simplest setting in which each agent's investment decision is zero-one and investment is socially productive, the result that assets should be owned by indispensable trading partners and that strictly complementary assets should be commonly owned will hold under weak assumptions. All we really require is that individual $i$ 's share of a fixed amount of surplus will be smaller the more people whose agreement he requires to capture this surplus. This is likely to be satisfied by any reasonable bargaining solution.

Once we depart from the simple zero-one case, however, the Shapley value and our other assumptions become more important. The driving force behind all our results is the idea that agents underinvest because some of the benefits from their investment are dissipated in future bargaining. Assets are allocated so as to mitigate this underinvestment. Once we allow more general specifications of the model, however, underinvestment is not inevitable. For example, if assumption 6 is violated, the left-hand side of (5) may exceed $v^{\imath}(\underline{S}, \underline{A} \mid x)$ and some agents may overinvest relative to the first-best. The same outcome can occur, even if assumption 6 holds, if we depart from the Shapley value and the marginal incentive to invest is no longer a weighted sum of the $v^{\imath}(S, A \mid x)$.

If agents overinvest relative to the first-best, far from wanting to increase investment incentives, they may want to reduce them. That is, holdups may be good, not bad! Thus it may be positively desirable to keep assets away from indispensable trading partners or split up complementary assets, in order to reduce incentives to invest and bring investment closer to its efficient level.

A similar possibility arises when agents must choose what type of action to take as well as what level. For instance, suppose that skill acquisition is costless, but agent 1 must decide at date 0 what type of skill to acquire. Assume that agent 1 will later trade with an indispensable agent 2 and another agent 3 , using a single asset $a$ (imagine that there are only three agents in the economy and that agents 2 and 3 do not invest). If agent 3 owns the asset, agent 1 will choose $x_{1}$ at date 0 to maximize $1 / 3 v(123, a \mid x)$ since he recognizes that he must reach agreement with both agents 2 and 3 to realize the date 1 gains from trade (see [4]). This yields the first-best. On the other hand, if agent 2 owns the asset, agent 1 maximizes $1 / 3 v(123, a \mid x)+1 / 6 v(12, a \mid x)$ (again by [4]). This is typically not first-best. We see then that when type of action rather than level of action is important, it may be better to give an asset to an agent who is not indispensable (agent 3) than to an agent 
who is (agent 2); doing so encourages the investing agent to select the type of skill that is appropriate for the grand coalition rather than for a subcoalition.

How important overinvestment and type of action effects are relative to underinvestment effects in empirical terms is, of course, hard to say. Note that, even in the presence of such effects, the framework we have put forward is helpful in determining optimal patterns of ownership.

Another strong assumption made is that ex post bargaining is efficient and inefficiencies arise only with respect to ex ante actions. We feel, however, that in stressing ex ante inefficiencies, we may be picking up some of the same effects that an ex post inefficiency model would generate. For example, an ad hoc way of introducing ex post inefficiencies is to assume that any ex post trade or agreement between two individuals will with some small probability not be consummated even if it is mutually advantageous. This implies roughly that assets should be allocated at date 0 so as to minimize the number of new agreements that have to be reached at date 1 . This suggests that an agent who is crucial for the generation of surplus should have ownership rights (agreement will have to be reached with the agent anyway, so why increase the number of agreements necessary by giving ownership rights to others), and that highly complementary assets should be owned together (since coordination of these assets is crucial, the total number of agreements is reduced by having one person control them all). But these conclusions are also implications of the ex ante analysis. In other words, the ex ante analysis appears able to capture some of the coordination issues that are central to an ex post perspective, in addition to incorporating the role of investment incentives. This is not to deny, of course, that in future work it would be very desirable to analyze the consequences of ex post inefficiencies in a systematic manner, for example, by introducing asymmetric information.

There are a number of other possible extensions of the analysis. Our model ignores payoff uncertainty, risk aversion, and wealth constraints. This means that the issue of how an investment should be financed and how ownership rights should be allocated between those who finance it and those who manage it plays no part in our analysis. Yet we believe that this issue is important for many firms. ${ }^{30}$ In addition, we have ignored issues having to do with the dissemination of information and with how coordination takes place between individuals with different sources of information but possibly similar goals. ${ }^{31}$

\footnotetext{
${ }^{30}$ Recent papers that investigate the financing issue are Aghion and Bolton (1988), Grossman and Hart (1988), Harris and Raviv (1988), and Hart and Moore (1989).

${ }^{31}$ This is the focus of the team theory literature (see Marschak and Radner 1972).
} 
An indication of this is that in our model an employer never has to tell an employee what to do: the employee simply figures it out himself and acts accordingly. It seems very desirable to relax this assumption in future work. Finally, we have supposed that each agent's investment or action enhances his own productivity, but not that of the assets he works with (see assumption 3). There is no reason, however, why the analysis could not be generalized to include asset-enhancing investments.

In spite of its restrictive assumptions, we believe that our analysis has identified some of the forces determining the boundaries of the firm. For example, it can explain why a firm faces first increasing and then decreasing returns to scale (increasing returns due to the positive benefits of coordinating complementary assets [proposition 8] and decreasing returns due to the inefficiencies of centralized control as new managers with economically independent roles must be brought in [proposition 10]). And, as we have seen in Section IV, it can throw light on ownership arrangements when several firms depend on a single supplier for an input (e.g., an oil pipeline). At the same time, the model in its present state cannot explain the delegation of control or the determination of hierarchical structure within a firm. Our hope is that such factors can be understood in generalizations of the model. In addition we hope that the model or its extensions will throw light on integration decisions in particular empirical contexts. $^{32}$ Our purpose in writing this paper has been to provide a framework for analysis; much remains to be done in the application of this framework and its further development.

\section{Appendix A}

In this Appendix, we prove propositions 1, 9, 11, and 12 .

\section{Proof of Proposition 1}

The Nash equilibrium investments $x_{i}^{e}(\alpha)$ are characterized by (5), which using assumption (3) can be rewritten as (restricting attention to those agents $i$ who have investments, $\bar{x}_{i}>0$ )

$$
\left.\nabla g(x ; \alpha)\right|_{x=x^{e}(\alpha)}=0,
$$

where

$$
g(x ; \alpha) \equiv\left[\sum_{\text {all } S} p(S) v(S, \alpha(S) \mid x)-\sum_{i=1}^{I} C_{i}\left(x_{i}\right)\right] .
$$

In principle there may be more than one vector $x^{e}(\alpha)$ satisfying (5). For the

${ }^{32}$ As discussed in Chandler (1977), say; for a survey of recent empirical work, see Joskow (1988). 
moment, for a given $\alpha$, select one such vector. In fact we shall prove uniqueness below.

Now consider the change in control structure from $\alpha$ to $\hat{\alpha}$ given in the proposition. By assumption, $\nabla g(x ; \hat{\alpha}) \geq \nabla g(x ; \alpha)$ for all $x$.

Define $f(x ; \lambda) \equiv \lambda g(x ; \hat{\alpha})+(1-\lambda) g(x ; \alpha)$ for $\lambda \in[0,1]$. Also define $x(\lambda)$ to solve $\nabla f(x ; \lambda)=0$. Totally differentiating, we obtain

$$
H(x ; \lambda) d x(\lambda)=-[\nabla g(x ; \hat{\alpha})-\nabla g(x ; \alpha)] d \lambda,
$$

where $H(x ; \lambda)$ is the Hessian of $f(x ; \lambda)$ (with respect to $x$ ). By assumptions 1 and $2, H(x ; \lambda)$ is negative definite. Also, by assumption 4 , the off-diagonal elements of $H(x ; \lambda)$ are nonnegative. So $H(x ; \lambda)^{-1}$ is a nonpositive matrix (see, e.g., Takayama 1985 , p. 393, theorem 4.D.3 [III"] and [IV"]). Hence $\partial x(\lambda) / \partial \lambda$ $\geq 0$, and $x(1) \geq x(0)$ or $x^{e}(\hat{\alpha}) \geq x^{e}(\alpha)$.

It is now trivial to confirm that the Nash equilibrium investments are unique for a given $\alpha$. Simply set $\hat{\alpha}=\alpha$ in the previous paragraphs and use the facts that $x^{e}(\hat{\alpha}) \geq x^{e}(\alpha)$ and $x^{e}(\alpha) \geq x^{e}(\hat{\alpha})$.

Similar reasoning can be used to show that $x^{e}(\alpha) \leq x^{*}$. Simply replace $g(x ; \hat{\alpha})$ in the argument above by the social surplus $W(x)$, and replace $f(x ; \lambda)$ by $\lambda W(x)$ $+(1-\lambda) g(x ; \alpha)$. As was pointed out in Section II, assumption 6 and condition (3) together imply $\nabla W(x) \geq \nabla g(x ; \alpha)$ for all $x$. By assumptions 1 and 2 , the Hessian of $W(x)$ is negative definite. The rest of the argument is the same; hence $x^{*} \geq x^{e}(\alpha)$.

Finally, since $\nabla W\left(x^{e}(\hat{\alpha})\right) \geq \nabla g\left(x^{e}(\hat{\alpha})\right)=0$ and $x^{e}(\hat{\alpha}) \geq x^{e}(\alpha)$, it follows from the concavity of $W(x)$ that $W\left(x^{e}(\hat{\alpha})\right) \geq W\left(x^{e}(\alpha)\right)$. Q.E.D.

\section{Proof of Proposition 9}

In this proposition, a control structure $\alpha$ may be stochastic. Suppose that under some realization of $\alpha$, an agent $k$ has some control rights even though he is dispensable and has no investment. Then consider a new stochastic control structure $\tilde{\alpha}$, which is the same as $\alpha$ except that (in this realization) agent $k$ 's control rights are now allocated randomly at date 1 to the other $I-$ 1 agents on an equal basis. It is straightforward to confirm that each realization of $\tilde{\alpha}$ satisfies (2) and (3), as required.

The expected change $E B_{i}^{i}(\tilde{\alpha})-B_{i}^{i}(\alpha)$ in marginal return on investment for some agent $i \neq k$ will be (let $s=|S|$ )

$$
\begin{aligned}
& \sum_{\left.S\right|_{k \notin S} ^{i \in S}} \frac{s}{I-1} p(S)\left[v^{i}(S, \alpha(S \cup\{k\}))-v^{i}(S, \alpha(S))\right]
\end{aligned}
$$

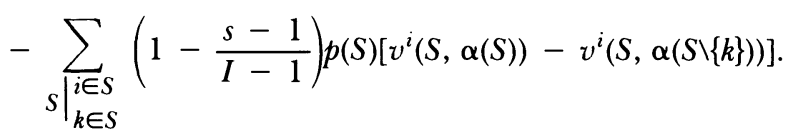

Since agent $k$ is dispensable, this equals

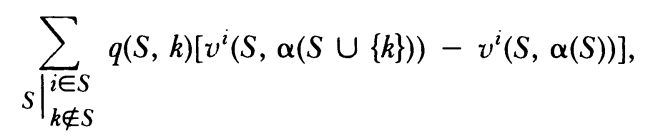


where

$$
\begin{aligned}
q(S, k) & =\frac{s}{I-1} p(S)-\left(1-\frac{s}{I-1}\right) p(S \cup\{k\}) \\
& =\frac{s !(I-s-1) !}{I !}\left[\frac{I-s}{I-1}-\left(1-\frac{s}{I-1}\right)\right] \\
& =\frac{s !(I-s-1) !}{I !}\left(\frac{1}{I-1}\right)>0 .
\end{aligned}
$$

Hence by assumption 6 , the marginal incentive to invest by any agent $i \neq k$ will not be reduced by the change in control structure. By assumption, agent $k$ himself has no investment. So from proposition 1, welfare will be higher under the new control structure $\tilde{\alpha}$ than under $\alpha$. Q.E.D.

\section{Proof of Proposition 11}

Suppose that asset $a_{n}$ is essential to agent $i$ and that under some control structure $\alpha$ another agent $j$ owns $a_{n}$. Then consider a new control structure $\hat{\alpha}$ in which $j$ owns all the assets $A$; $\tilde{\alpha}$ trivially satisfies requirements (2) and (3). be

The change $B_{i}^{i}(\hat{\alpha})-B_{i}^{i}(\alpha)$ in marginal return on investment for agent $i$ will

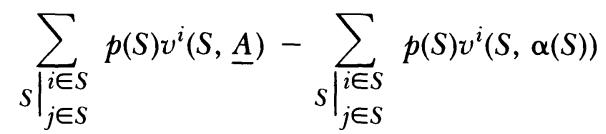

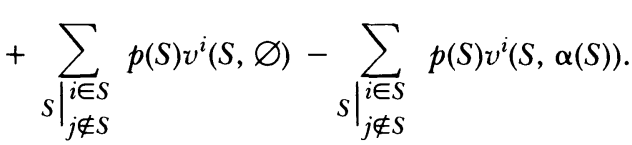

The last summation is zero because $j \notin S$ implies $a_{n} \notin \alpha(S)$ and, by assumption, $a_{n}$ is essential to agent $i$. Also, assumption 6 implies that the first summation is no less than the second. So, if the effects of changes in other agents' investment levels are ignored, agent $i$ 's marginal incentive to invest will be increased by the change in control structure. Q.E.D.

\section{Proof of Proposition 12}

Suppose that $\alpha$ is a control structure in which agent $j$ owns asset $a^{*}$ and agent $i$ owns asset $a$. Define a new control structure $\hat{\alpha}$, which is the same as $\alpha$ except that now agent $j$ exercises all the control that agent $i$ used to exercise under $\alpha$. It is straightforward to confirm that $\hat{\alpha}$ satisfies requirements (2) and (3).

In what follows, we ignore the effect of changes in the level of investment by agents other than agents $i, j$, and $\{w\}$. Clearly, agent $j$ 's marginal incentive to invest will be higher under $\hat{\alpha}$ than under $\alpha$ since he now controls more assets. Agent $i$ 's incentives will not change: under both $\alpha$ and $\hat{\alpha}$, he has to be in a coalition with $j$ in order to gain access to $a^{*}$, so it does not matter that $j$ has his control rights.

The change $B_{w}^{w}(\hat{\alpha})-B_{w}^{w}(\alpha)$ in marginal return on investment for a worker $w$ will be 


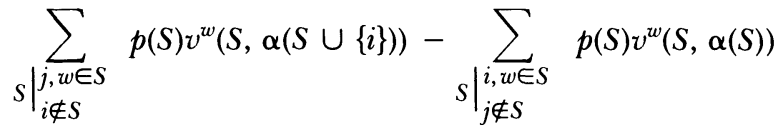

$$
\begin{aligned}
& +\sum_{\substack{i, w \in S \\
j \notin S}} p(S) v^{w}(S, \alpha(S \backslash\{i\}))-\sum_{\substack{j, w \in S \\
i \notin S}} p(S) v^{w}(S, \alpha(S)) .
\end{aligned}
$$

The last two summations are both zero because if a coalition does not contain agent $i$, then under $\alpha$ it does not control $a$, which is essential to $w$. The first summation is no less than the second because of assumption 6 together with the facts that (i) agent $i$ is dispensable and (ii) $p(S)$ is a function only of the size, not of the composition, of coalition $S$. Thus $w$ 's marginal incentive to invest will be increased by the change in control structure. Q.E.D.

\section{Appendix B}

In the model of Section II, agents make investments in human capital at date 0 that affect their productivities at date 1 . In this Appendix, we briefly extend the model to learning by doing and signaling activities.

\section{Learning by Doing}

This is a slight variant on the model of Section II. During period 0 , each agent $i$ works an amount $x_{2}$ (rather than simply invests in training). However, he learns as he works; and so, as in Section II, the total value $V(x)$ at date 1 will be an increasing function of $\left(x_{1}, \ldots, x_{I}\right)$. The only new effect is that during period 0 , in addition to the cost $C_{\imath}\left(x_{\imath}\right)$, each agent $i$ receives a (private) benefit $w_{i}(x)$, which represents his share of the fruits of date 0 production. Since $w_{i}$ in general depends on $x_{j}$ as well as $x_{\imath}$, this creates further externalities. Typically, though, these will serve only to reinforce the underactivity of proposition 1 because of the usual moral hazard effect in teams. Hence all the propositions and results from Sections III and IV apply. For a formal model, see Hart and Moore (1988, sec. 5).

\section{Signaling Type through Choice of Action}

In this model agents have unknown abilities, for example, their aptitude, trustworthiness, loyalty, or simply their willingness to work hard. There is no training or learning by doing during period 0 . Rather, an agent works hard at date 0 in order to convince other agents that he is of high ability. That way, he will be in a position to command a larger share of the date 1 total value. As in Sections III and IV, he will have a greater incentive to work hard if, for example, assets that are important to him are owned by people who are important to him. In short, it matters who his boss is. An optimal control structure distributes ownership of assets so as to provide the best overall incentives for agents to work hard at building their reputations.

In Hart and Moore (1988), this idea is formalized using Holmstrom's (1982) model of reputation. Suppose that each agent $i$ has a true ability $\theta_{l}$, drawn from a publicly known ex ante distribution. In period 0 , agent $i$ (know- 
ing the distribution of $\theta_{i}$ but not its value) takes an uncontractible action $x_{i}$, for example, effort. All agents then observe $y_{i}=x_{i}+\theta_{i}$, but $x_{i}$ remains unobservable to agents other than $i$. This means that, given a period 0 Nash equilibrium of actions $x_{i}^{e}$, the other agents conclude that agent $i$ has ability $\theta_{i}=y_{i}-$ $x_{i}^{e}$. At date 1 , the (perceived) total value is divided according to the Shapley value, with each agent's share being sensitive to the perceived vector of abilities. (No further effort is exerted in the second period since, given that the world ends after this, there is no reason to build any further reputation.)

Given this structure, each agent $i$ will have an incentive to take effort at date 0 to persuade other agents that his ability, which they measure as $y_{i}-x_{i}^{e}$, is high. (Notice that in equilibrium the market is not fooled. However, this does not mean that the agent can slack; he still has to work hard so as not to convey a poor signal about his ability and lose his reputation.) Moreover, the extent to which agent $i$ tries to persuade others about his ability will depend on how much his bargaining power would be improved by his being perceived as being able; this in turn will depend on $\alpha$, the allocation of assets at date 1 . A good control structure $\alpha$ will encourage agents to work hard at building their reputations in order to alleviate the moral hazard problem at date 0 . The propositions and results from Sections III and IV can be shown to apply; for details, see Hart and Moore (1988, sec. 5).

Here we are narrowly interpreting $x_{i}$ as effort. However, we believe that a suitably modified model would admit broader interpretations. For example, $x_{i}$ could stand for a particular type of action selected by the employee (which of several tasks to carry out), with the idea being that an agent $i$ may choose a particular $x_{i}$ at date 0 (e.g., he may carry out the task requested by his boss) because he wants to signal that he is a particular type of worker (e.g., that he is obedient, willing, trustworthy, or loyal).

\section{References}

Aghion, Philippe, and Bolton, Patrick. “An 'Incomplete Contracts' Approach to Bankruptcy and the Optimal Financial Structure of the Firm." Manuscript. Berkeley: Univ. California, 1988.

Alchian, Armen A., and Demsetz, Harold. "Production, Information Costs, and Economic Organization." A.E.R. 62 (December 1972): 777-95.

Arrow, Kenneth J. The Limits of Organization. New York: Norton, 1974.

Aumann, Robert J., and Kurz, Mordecai. "Power and Taxes." Econometrica 45 (July 1977): 1137-61.

Becker, Gary S. Human Capital: A Theoretical and Empirical Analysis, with Special Reference to Education. New York: Columbia Univ. Press (for NBER), 1964.

Chandler, Alfred D., Jr. The Visible Hand: The Managerial Revolution in American Business. Cambridge, Mass.: Harvard Univ. Press, 1977.

Coase, Ronald H. "The Nature of the Firm." Economica 4 (November 1937): 386-405. Reprinted in Readings in Price Theory, edited by George J. Stigler and Kenneth E. Boulding. Homewood, Ill.: Irwin (for American Econ. Assoc.), 1952.

$\rightarrow$ Grossman, Sanford J., and Hart, Oliver D. "The Costs and Benefits of Ownership: A Theory of Vertical and Lateral Integration." J.P.E. 94 (August 1986): 691-719.

- "One Share-One Vote and the Market for Corporate Control." J. Financial Econ. 20 (January/March 1988): 175-202. 
Gul, Faruk. "Bargaining Foundations of Shapley Value." Econometrica 57 (January 1989): 81-95.

Harris, Milton, and Raviv, Artur. "Corporate Governance: Voting Rights and Majority Rules.” J. Financial Econ. 20 (January/March 1988): 203-35.

$\rightarrow$ Hart, Oliver. "An Economist's Perspective on the Theory of the Firm." Columbia Law Rev. 89 (November 1989): 1757-74.

Hart, Oliver, and Moore, John. "Property Rights and the Nature of the Firm.” Working Paper no. 495. Cambridge: Massachusetts Inst. Tech.; Discussion Paper no. TE/88/174. London: London School Econ., SuntoryToyota Internat. Centre Econ. and Related Disciplines, 1988.

. "Default and Renegotiation: A Dynamic Model of Debt." Manuscript. Cambridge: Massachusetts Inst. Tech.; London: London School Econ., 1989.

Hart, Sergiu. "Shapley Value." In The New Palgrave: A Dictionary of Economics, edited by John Eatwell, Murray Milgate, and Peter Newman. London: Macmillan, 1987.

Holmstrom, Bengt. "Managerial Incentive Problems-a Dynamic Perspective." In Essays in Economics and Management in Honor of Lars Wahlbeck. Helsinki: Swedish School Econ., 1982.

Holmstrom, Bengt, and Tirole, Jean. "The Theory of the Firm.” In Handbook of Industrial Organization, edited by Richard Schmalensee and Robert Willig. Amsterdam: North-Holland, 1989.

$\rightarrow$ Joskow, Paul L. "Asset Specificity and the Structure of Vertical Relationships: Empirical Evidence." J. Law, Econ., and Organization 4 (Spring 1988): 95117.

$\rightarrow$ Kalai, Ehud, and Samet, Dov. "Monotonic Solutions to General Cooperative Games.” Econometrica 53 (March 1985): 307-27.

- "Weighted Shapley Values." In The Shapley Value: Essays in Honour of Lloyd S. Shapley, edited by Alvin E. Roth. New York: Cambridge Univ. Press, 1988.

$\rightarrow$ Klein, Benjamin; Crawford, Robert G.; and Alchian, Armen A. "Vertical Integration, Appropriable Rents, and the Competitive Contracting Process." J. Law and Econ. 21 (October 1978): 297-326.

Marschak, Jacob, and Radner, Roy. Economic Theory of Teams. New Haven, Conn.: Yale Univ. Press, 1972.

Milgrom, Paul, and Roberts, John. "Rationalizability, Learning and Equilibrium in Games with Strategic Complementarities." Econometrica (in press).

Owen, Guillermo. Game Theory. 2d ed. New York: Academic Press, 1982.

Roth, Alvin E., ed. The Shapley Value: Essays in Honour of Lloyd S. Shapley. New York: Cambridge Univ. Press, 1988.

Rydqvist, K. "Empirical Investigation of the Voting Premium.” Manuscript. Evanston, Ill.: Northwestern Univ., 1987.

Shapley, Lloyd S. "A Value for n-Person Games.” In Contributions to the Theory of Games, vol. 2, edited by Harold W. Kuhn and Albert W. Tucker. Princeton, N.J.: Princeton Univ. Press, 1953.

$\rightarrow$ Simon, Herbert A. "A Formal Theory of the Employment Relationship." Econometrica 19 (July 1951): 293-305.

Takayama, Akira. Mathematical Economics. 2d ed. Hinsdale, Ill.: Dryden, 1985.

Williamson, Oliver E. Markets and Hierarchies: Analysis and Antitrust Implications. New York: Free Press, 1975.

- The Economic Institutions of Capitalism: Firms, Markets, Relational Contracting. New York: Free Press, 1985. 